\title{
Composites Containing Waste Materials
}

\author{
Milena Koleva1 ${ }^{1}$ Anka Zheglova1, \\ Venceslav Vassilev ${ }^{2}$ and Emilija Fidancevska ${ }^{3}$ \\ ${ }^{1}$ Technical University of Gabrovo \\ ${ }^{2}$ University of Chemical Technology and Metallurgy, Sofia \\ 3"St. Cyril and Methodius" University, Skopie \\ 1,2Bulgaria \\ ${ }^{3}$ Republic of Macedonia
}

\section{Introduction}

In the development of new materials, apart from the properties of the materials, the economic and ecological aspects are also of considerable importance. Traditional products whose manufacture requires expensive raw materials are being replaced with composite materials with alternative properties which display better qualities and perform in a better way. Composite materials are obtained from much cheaper components and possess significantly lower relative weight.

Over the last few years different kinds of waste materials have been successfully utilized as filler in polymer composites with various applications. This not only reduces the production costs but also offers an opportunity for utilization of waste materials thereby reducing environmental pollution. Among them a large number of insulation composite materials with different practical application have been developed.

Many of the composites are thermal, electrical or noise insulating materials based on thermosetting polymers (polyester and epoxy resins) which combine the required physical characteristics with good processing properties. For example polyester resins have a series of valuable properties - suitable viscosity, ability to solidify at both room and high temperatures, high electric strength and dielectric ratings, high chemical stability and etc. Experimental research shows that the properties of the composites in this case are a function of both the curing degree of the polymer and the kind and properties of the filler.

At the same time there are organic or inorganic waste materials generated by the industrial processes or human activity, which could successfully replace or at least reduce the amount of raw materials used as components in insulation materials.

This chapter presents the outcomes of the experimental work aimed to evaluate the possibility for utilization of organic and inorganic industrial waste as fillers in polymer composites with thermal- and electrical insulation and sound damping properties.

\section{Inorganic composite materials based on industrial wastes}

\subsection{Metallurgical slag}

Recycling whereby metallurgical wastes are decreased is one of the most important processes for environmental protection. Metallurgical slag (ferronickel, ferrochromium, 
calcium ferrite, etc.) is the main waste of ore processing in metallurgy. It is a multicomponent system characterized by high percentage content of $\mathrm{Si}-, \mathrm{Ca}-, \mathrm{Fe}-$ and $\mathrm{Mg}$ oxides with high porosity related to the presence of glassy phase (5-30\%). In this sense the usage of metallurgical slag as raw base for production of new materials is useful for many other productions.

At controlled thermal treatment metallurgical wastes and glass can be used to obtain compact and porous glass-ceramic materials, which are used for production of electronic elements, catalysts, membranes, composite materials, etc. Metallurgical slag rich in Si- and Al-oxides can be used as material for ceramic filters, aerators and diffusers for treatment of industrial gases and waste waters purification. The obtained glass-ceramic products are resistant to harsh thermal changes and possess good chemical, physical, microbiological and mechanical properties.

The aim of this experimental work was to study the possibility for utilization of metallurgical ferronickel (Fe-Ni) slags. Two types of metallurgical slags are used: from the "refining" (Slag-R) and from the "melting" (Slag-M) processes. By their chemical composition these are multicomponent silicate systems with high content of $\mathrm{Fe}_{2} \mathrm{O}_{3}, \mathrm{FeO}, \mathrm{SiO}_{2}, \mathrm{CaO}$ and $\mathrm{MgO}$. The grain size analysis shows that the highest is the fraction with particles size $<0.045$

$\mathrm{mm}$. The Slag- $\mathrm{R}$ phase composition includes escolite $\left(\mathrm{Cr}_{2} \mathrm{O}_{3}\right)$ and amorphous phase, while the Slag-M is consisted of hematite $\left(\mathrm{Fe}_{2} \mathrm{O}_{3}\right)$, diopside $\left(\mathrm{CaMgSi}_{2} \mathrm{O}_{6}\right)$, olivine $\left(\mathrm{MgFeSiO}_{4}\right)$ and amorphous phase.

Both slags possess different thermal characteristics: Slag-R has wider sintering interval $\left(1250-1500^{\circ} \mathrm{C}\right)$ than this of Slag-M $\left(1260-1370^{\circ} \mathrm{C}\right)$. The glass-transition and the melting temperatures of Slag-R $\left(1500\right.$ and $\left.>1500^{\circ} \mathrm{C}\right)$ are higher than these of Slag-M (1370 and $1480^{\circ} \mathrm{C}$ ), which is due to the higher content of hard melting oxides in it.

The green density of Slag-R and Slag-M are 5,04 g/ $\mathrm{cm}^{3}$ and 3,58 g/ $\mathrm{cm}^{3}$, respectively.

The thermomechanical properties of the Fe-Ni-slag are investigated on pressed samples with the shape of rectangular prism $\left(60 \times 5 \times 5 \mathrm{~mm}^{3}\right)$, as fraction with particles size $<0.045$ $\mathrm{mm}$; pressing pressure of $30 \mathrm{MPa}$; plastifyer $-1 \%$ solution of polyvinyl alcohol (PVA) is used. Synthesis is conducted at $\mathrm{T}=900 \div 1200^{\circ} \mathrm{C}\left(\Delta 50^{\circ} \mathrm{C}\right)$ in chamber furnace (air atmosphere; heating rate of $10^{\circ} \mathrm{C} / \mathrm{min}$; isothermal hold at the final temperature of $2 \mathrm{~h}$ ). Slag- $\mathrm{R}$ increases its geometrical stability when the synthesis temperature is increased up to $1200^{\circ} \mathrm{C}$ whereas Slag-M samples are deformed at $\mathrm{T}>1150^{\circ} \mathrm{C}$ as a result of gas removal from their volume.

The technical coefficient of linear thermal expansion $\left(\alpha_{\text {tech }}\right)$ for both types of slagis in the interval $20-600^{\circ} \mathrm{C}$ is: $12,9.10^{-6}{ }^{\circ} \mathrm{C}^{-1}$ (Slag-R) and $11,6.10^{-6}{ }^{\circ} \mathrm{C}^{-1}$ (Slag-M) (Fidancevska et al., 2006).

Synthesis temperature influences the main properties of the compacts produced from the two slag types which is due to their different reactivity and significant differences in their chemical and phase composition - Table 1.

\subsection{Waste glass}

Waste glass (from windows, packages and TV sets) is used as initial material for production of glass-ceramic materials in many European countries. The waste window glass is recycled $(\approx 26 \%)$ and returned for secondary melting. The packages glass is recycled depending on its color: $82,0 \%$ green, $44,5 \%$ brown and $43,8 \%$ white glass. From ecological point of view the windows and containers glass are harmless and can be used as initial material for blocking of harmful and dangerous for the environment elements. 
Waste glass from TV monitors, windows and packages is used as source of glassy phase in the experiments for production of "glass-ceramic" composites. The TV-glass differs from the other two types by the presence of $\mathrm{PbO}(8,18 \%)$ and $\mathrm{K}_{2} \mathrm{O}(6,4 \%)$. Glass from window panes has higher $\mathrm{CaO}$ content than the package glass: 8.96 versus $0,21 \%$, while the package glass has higher concentration of $\mathrm{K}_{2} \mathrm{O}, \mathrm{MgO}$ and $\mathrm{B}_{2} \mathrm{O}_{3}$ than this of the windows glass: 2,31, 7,34 and 4,00 versus $0,19,3,62$ and $0,00 \%$, respectively.

Window panes and package glass are subject to direct crushing and milling and the TVglass is preliminary treated with $12 \% \mathrm{HF}$ solution for the purpose of removing the chemical components deposited on the TV screen. TV-glass has lower glass-transition temperature $\left(700^{\circ} \mathrm{C}\right)$ than the other types of waste glass: $\left(850^{\circ} \mathrm{C}\right)$ which is due to the presence of $\mathrm{PbO}$ and $\mathrm{K}_{2} \mathrm{O}$ in it. For this reason TV-glass is appropriate for usage in composite systems. The complete melting temperature of the TV-glass $\left(800^{\circ} \mathrm{C}\right)$ is lower than this of the window panes $\left(950^{\circ} \mathrm{C}\right)$ and the package glass $\left(960^{\circ} \mathrm{C}\right)$. To strengthen waste glass a powder fraction with particles sizes $<45 \mu \mathrm{m}$ is used as is the case with metallurgical slag. The compacts are produced in a way identical to that of the slag, however, it is carried out at lower synthesis temperature $\left(600-800^{\circ} \mathrm{C}\right)$ and holding at the maximum temperature for $1 \mathrm{~h}$ (Vassilev et al., 2007a).

The main properties of the sintered compacts from the three types of waste glass are presented in Table 1 . Linear thermal expansion coefficient $\left(\alpha_{\text {tech }}\right)$ in the interval $20-600^{\circ} \mathrm{C}$ is: $10,6 \cdot 10^{-6}{ }^{\circ} \mathrm{C}^{-1}$ (TV-glass); $10,1.10^{-6}{ }^{\circ} \mathrm{C}^{-1}$ (window panes glass) and $10,8.10^{-6}{ }^{\circ} \mathrm{C}^{-1}$ (package glass).

TV-glass is the most appropriate for production of glass-ceramic composites because of its sintering temperature, mechanical properties and technical coefficient of linear thermal expansion.

\begin{tabular}{|c|c|c|c|c|c|}
\hline Waste & $\begin{array}{c}\text { Synthesis } \\
\text { temperature, } \\
{ }^{\circ} \mathrm{C}\end{array}$ & $\begin{array}{c}\text { Density (d), } \\
\mathrm{g} / \mathrm{cm}^{3}\end{array}$ & $\begin{array}{l}\text { Porosity } \\
\quad(\theta), \%\end{array}$ & $\begin{array}{c}\text { Young } \\
\text { modulus (E), } \\
\text { GPa }\end{array}$ & $\begin{array}{c}\text { Bending } \\
\text { strength }(\sigma), \\
\mathrm{MPa}\end{array}$ \\
\hline \multirow{3}{*}{ Slag-R } & 1100 & 3,21 & 36,3 & 27,3 & 41,5 \\
\hline & 1150 & 3,25 & 35,5 & 29,0 & 47,8 \\
\hline & 1200 & 3,28 & 34,9 & 39,4 & 48,7 \\
\hline \multirow{6}{*}{ Slag-M } & 900 & 2,25 & 37,2 & 6,1 & 11,5 \\
\hline & 950 & 2,36 & 34,1 & 6,2 & 14,0 \\
\hline & 1000 & 2,38 & 33,5 & 6,7 & 17,8 \\
\hline & 1050 & 2,48 & 30,7 & 16,1 & 26,0 \\
\hline & 1100 & 2,76 & 22,9 & 25,2 & 49,9 \\
\hline & 1150 & 2,93 & 18,2 & 29,1 & 51,0 \\
\hline TV-glass & 600 & 2,61 & - & 72,0 & 136,0 \\
\hline Windows glass & 750 & 2,66 & - & 50,0 & 125,0 \\
\hline Packages glass & 800 & 2,54 & - & 52,0 & 127,0 \\
\hline
\end{tabular}

Table 1. Density, porosity and mechanical properties of metallurgical slags: Slag-R and Slag-M and waste glass: TV, windows and packages 


\subsection{Composites based on Fe-Ni slag and waste glass}

Environmental protection from the huge quantities of metallurgical and glass wastes by utilizing them as ingredients of different composites with wide range of possible application is a subject matter of proper addressing a challenge of urgent actuality. Here is shown one of the possibilities for production of composites based on metallurgical slag (Slag-R and Slag$\mathrm{M})$ and waste glass.

Composites based on metallurgical slag and waste glass are produced by mechanically mixing the two components as the glass content in them varies from 10 to $50 \mathrm{wt}$. \%. The conditions at which the composites are obtained are similar to these used for obtaining compacts from the initial components (slag and glass).

Composites (Slag-R+10\% TV-glass) and (Slag-R+20 \% TV-glass) are sintered at $\mathrm{T}=1100$, 1150 and $1500^{\circ} \mathrm{C} / 2 \mathrm{~h}$. They show significant deformation even at $1100^{\circ} \mathrm{C}$ which increases with the rise of temperature. With composites (Slag- $\mathrm{R}+20 \%$ windows glass) is observed deformation at sintering temperature $\geq 1200^{\circ} \mathrm{C} / 2 \mathrm{~h}$, caused by the significantly lower melting temperature of the TV-glass compared to this of the windows. Their properties are shown in Table 2.

\begin{tabular}{|c|c|c|c|c|c|}
\hline Composition & $\begin{array}{c}\text { Synthesis } \\
\text { temperature, } \\
{ }^{\circ} \mathrm{C}\end{array}$ & $\begin{array}{c}\text { Bending } \\
\text { strength } \\
(\sigma), \mathrm{MPa}\end{array}$ & $\begin{array}{c}\text { Young } \\
\text { modulus } \\
(\mathrm{E}), \mathrm{GPa}\end{array}$ & $\begin{array}{c}\text { Density (d), } \\
\mathrm{g} / \mathrm{cm}^{3}\end{array}$ & $\begin{array}{c}\text { Porosity } \\
(\theta), \%\end{array}$ \\
\hline Slag-R + 10\% TV-glass & 1100 & 43,5 & 33,1 & 3,20 & 33 \\
\hline Slag-R + 20\% TV-glass & 1100 & 45,0 & 37,6 & 3,33 & 27 \\
\hline \multicolumn{6}{|c|}{ Composite (Slag-R $+20 \%$ TV-glass $) \rightarrow \alpha=10,9.10^{-6}{ }^{\circ} \mathrm{C}\left(20-600{ }^{\circ} \mathrm{C}\right)$} \\
\hline Slag-R + 20\% TV-glass & 1100 & 45,0 & 37,6 & 3,33 & 27 \\
\hline Slag-R + 20\% TV-glass & 1150 & 49,2 & 42,2 & 3,60 & 21 \\
\hline
\end{tabular}

Table 2. Bending strength, Young modulus, density and porosity of composite Slag-R+glass depending on the composition and the synthesis temperature

The real density, porosity, elasticity modulus and bending strength of these composites are presented in Table 3 (depending on the composition) and in Table 4 (depending on the composition and the synthesis temperature).

\begin{tabular}{|c|c|c|c|c|c|}
\hline Composition & $\begin{array}{c}\text { Synthesis } \\
\text { temperature, } \\
{ }^{\circ} \mathrm{C}\end{array}$ & $\begin{array}{c}\text { Bending } \\
\text { strength } \\
(\sigma), \mathrm{MPa}\end{array}$ & $\begin{array}{c}\text { Young } \\
\text { modulus } \\
(\mathrm{E}), \mathrm{GPa}\end{array}$ & $\begin{array}{c}\text { Density (d), } \\
\mathrm{g} / \mathrm{cm}^{3}\end{array}$ & $\begin{array}{c}\text { Porosity } \\
(\theta), \%\end{array}$ \\
\hline Slag-M + 10\% TV-glass & 900 & 16,67 & 10,47 & 2,28 & 36 \\
\hline Slag-M + 20\% TV-glass & 900 & 27,06 & 15,10 & 2,26 & 35 \\
\hline Slag-M + 30\% TV-glass & 900 & 27,25 & 15,12 & 2,23 & 34 \\
\hline Slag-M + 40\% TV-glass & 900 & 30,13 & 16,69 & 2,14 & 34 \\
\hline Slag-M + 50\% TV-glass & 900 & 31,08 & 20,07 & 2,11 & 33 \\
\hline
\end{tabular}

Table 3. Bending strength, Young modulus, density and porosity of composite Slag-M+glass depending on the composition

The composites (Slag-M+waste glass), synthesized at $1150^{\circ} \mathrm{C} / 2 \mathrm{~h}$, are completely melt at the sintering temperature if one of the waste glasses participates in their composition in 
concentrations of 30,40 or $50 \mathrm{wt}$. \%. This means that the composites with such waste glass concentrations are practically inapplicable and that is why they are not included in Table 4 .

As seen from Tables 2, 3 and 4 when waste glass concentration is increased the bending strength and the elasticity modulus increase by absolute value regardless of the slag composition. The influence of the synthesis temperature is the same, however, at significantly higher degree. Meanwhile the composites' porosity decreases with the increase of their density.

\begin{tabular}{|c|c|c|c|c|c|}
\hline Composition & \begin{tabular}{|c|}
$\begin{array}{c}\text { Synthesis } \\
\text { temperature, } \\
{ }^{\circ} \mathrm{C}\end{array}$ \\
\end{tabular} & $\begin{array}{l}\text { Bending } \\
\text { strength } \\
(\sigma), \mathrm{MPa}\end{array}$ & $\begin{array}{l}\text { Young } \\
\text { modulus } \\
(\mathrm{E}), \mathrm{GPa}\end{array}$ & $\begin{array}{c}\text { Density } \\
(\mathrm{d}), \mathrm{g} / \mathrm{cm}^{3}\end{array}$ & $\begin{array}{c}\text { Porosity } \\
(\theta), \%\end{array}$ \\
\hline \multirow{6}{*}{$\begin{array}{c}\text { Slag-M+20\% } \\
\text { TV-glass } \\
\left(\alpha_{\text {tech }}=11,1.10^{-6}{ }^{\circ} \mathrm{C}\right) \\
\left(20-600^{\circ} \mathrm{C}\right)\end{array}$} & 900 & 27,06 & 15,10 & 2,26 & 35 \\
\hline & 950 & 28,58 & 16,07 & 2,31 & 34 \\
\hline & 1000 & 35,37 & 17,05 & 2,36 & 32 \\
\hline & 1050 & 53,97 & 23,06 & 2,42 & 30 \\
\hline & 1100 & 57,05 & 40,10 & 2,75 & 21 \\
\hline & 1150 & 64,08 & 47,95 & 3,34 & 4 \\
\hline \multirow{6}{*}{$\begin{array}{c}\text { Slag-M+20\% } \\
\text { windows glass } \\
\left(\alpha_{\text {tech }}=11,5.10^{-6}{ }^{\circ} \mathrm{C}\right) \\
\left(20-600^{\circ} \mathrm{C}\right)\end{array}$} & 900 & 18,06 & 10,23 & 2,03 & 42 \\
\hline & 950 & 19,33 & 11,15 & 2,14 & 39 \\
\hline & 1000 & 19,76 & 11,65 & 2,20 & 37 \\
\hline & 1050 & 42,34 & 17,59 & 2,35 & 33 \\
\hline & 1100 & 53,65 & 22,41 & 2,57 & 26 \\
\hline & 1150 & 60,98 & 34,39 & 2,98 & 15 \\
\hline \multirow{6}{*}{$\begin{array}{c}\text { Slag-M+20\% } \\
\text { containers glass } \\
\left(\alpha_{\text {tech }}=11,4.10^{-6}{ }^{\circ} \mathrm{C}\right) \\
\left(20-600^{\circ} \mathrm{C}\right)\end{array}$} & 900 & 12,34 & 7,14 & 2,11 & 39 \\
\hline & 950 & 20,44 & 8,80 & 2,14 & 38 \\
\hline & 1000 & 28,31 & 15,28 & 2,14 & 38 \\
\hline & 1050 & 48,73 & 20,43 & 2,34 & 33 \\
\hline & 1100 & 56,92 & 24,71 & 2,58 & 26 \\
\hline & 1150 & 77,41 & 39,93 & 2,92 & 16 \\
\hline
\end{tabular}

Table 4. Bending strength, Young modulus, density and porosity of composite Slag-M+glass depending on the composition and the synthesis temperature

If the mechanical properties ( $\sigma$ and E), density $(d)$, porosity $(\theta)$ and technical coefficient of linear thermal expansion $\left(\alpha_{\text {tech }}\right)$ are taken as criterion for selection of composite then the best qualities are displayed by the composite (Slag-M+20\% TV-glass) sintered at $1150^{\circ} \mathrm{C} / 2 \mathrm{~h}$. It is characterized by porosity of $4 \%$, i.e. $96 \%$ of the theoretical density and the best mechanical properties at the same time. According to the microstructural analysis the slag's particles are capsulated by melted glassy, partially crystallized phase (Fidancevska et al., 2007).

\subsection{Porous composites based on Fe-Ni slag and waste glass}

For the production of porous composites metallurgical Fe-Ni slag and waste TV-glass were used. The values of the composite properties are presented in Table 1 (shaded rows). 


\subsubsection{Porous composites based on coarse-grained slag}

A liquid glass layer is formed around the slag's particles by this method. If the slag is with larger grain size, the possibility for formation of contact between them is smaller and there is more free space between them. At temperatures higher than the complete melting temperature of the glass liquid bridges along with liquid glass film are also formed between the particles which dry up during sintering. The magnitude and the shape of the obtained pores depend on the slag's particles sizes.

Slag-M, preliminary milled in ball grinder, is divided to fractions with different particles sizes. For the production of porous composites are used: slag with particles size between $1,0+0,5 \mathrm{~mm} ;-0,50+0,25 \mathrm{~mm}$ and $-0,250+0,125 \mathrm{~mm}$ and powder from TV-glass with particles size $<0.045 \mathrm{~mm}$. The content of the TV-glass in the composites is 20, 30 and $40 \mathrm{wt}$. \%, respectively. From the composite press-powder (Slag-M+TV-glass+plastifyer PVA) are pressed samples with different shape at pressure of $30 \mathrm{MPa}$. The press-samples are sintered in air atmosphere at temperatures of 900,950 or $1000^{\circ} \mathrm{C}$ during $2 \mathrm{~h}$ (heating rate of $\left.10^{\circ} \mathrm{C} / \mathrm{min}\right)$.

With the increase of the sintering temperature, the composites containing Slag-M with larger grains (fraction $-1,0+0,5$ ) show salient tendency to melting and deformation. Conversely, the composites containing Slag-M with smaller grains (fraction $-0,250+0,125$ ) are steady to thermal treatment up to $\mathrm{T} \geq 1000^{\circ} \mathrm{C}$.

From the produced row of porous composites only those which possess optimal mechanical characteristics are selected. The density, porosity and mechanical properties taken as selection criterion determine as optimal the composite (Slag-M+40 \% TV-glass) with slag's particles size $-0,250+0,125 \mathrm{~mm}$, sintered at $950^{\circ} \mathrm{C} / 2 \mathrm{~h}$. It shows the lowest porosity of $26.8 \%$ and the best mechanical characteristics - Table 5 .

\begin{tabular}{|c|c|c|c|c|c|}
\hline Composite & $\mathrm{T}_{\text {synth }}{ }^{\circ} \mathrm{C}$ & $\rho, \mathrm{g} / \mathrm{cm}^{3}$ & $\theta, \%$ & $\sigma, \mathrm{MPa}$ & $\mathrm{E}, \mathrm{GPa}$ \\
\hline Slag-M -0,250+0,125 mm $+40 \%$ TV-glass & 900 & 2,27 & 30,5 & 29,47 & 17,51 \\
\hline Slag-M -0,250+0,125 mm $+40 \%$ TV-glass & 950 & 2,39 & 26,8 & 29,28 & 21,25 \\
\hline Slag-M -0,250+0,125 mm $+40 \%$ TV-glass & 1000 & 2.26 & 30.8 & 33.19 & 21.22 \\
\hline
\end{tabular}

Table 5. Density, porosity and mechanical properties of composite [Slag-M (fraction -1.0+0.5) + $20 \%$ TV-glass] depending on the synthesis temperature

Solubility in aggressive media $\left(0,1 \mathrm{~mol} / \mathrm{dm}^{3} \mathrm{HCl}\right.$ and $\left.0,1 \mathrm{~mol} / \mathrm{dm}^{3} \mathrm{Na}_{2} \mathrm{CO}_{3}\right)$ is low and varies between $0,02-0,20 \%$.

The cross-section of this composite shows presence of closed type micro-pores with sizes of 5-10 $\mu \mathrm{m}$, which are formed during sintering, and opened pores with sizes of 250-500 $\mu \mathrm{m}$, connected to the voids between the slag grains soldered with the glassy phase. These macropores are interconnected through the whole composite volume, due to which it can be used as diffuser for air aeration (Vassilev et al., 2007b).

\subsubsection{Porous composites with gradient (multilayer) structure}

These types of composites are characterized by linear porosity gradient. They are formed by 2(3) layers with different porosity. The upper layer is composite slag+glass with slag's particles $\leq 45 \mu \mathrm{m}$. The porosity of this layer is controlled by the sintering conditions. The second (third) layer is composite with slag's fractions $-1,0+0.5,-0,50+0,25$ and $-0,250+0,125$ $\mathrm{mm}$ and glass fraction $<45 \mu \mathrm{m}$. The porosity of these layers is significantly higher than this of the first layer since one works with larger particles of the metallurgical slag. Three 
sintering temperatures are investigated: 900,950 and $1000^{\circ} \mathrm{C}$ (pressing pressure of $30 \mathrm{MPa}$, air atmosphere).

Composites (Slag-M+TV-glass) in which the slag is with particles size of $-1,0+0.5 \mathrm{~mm}$ do not yield thermal treatment above $950^{\circ} \mathrm{C} / 2 \mathrm{~h}$ since deformation of samples occurs. For samples with smaller slag particles $(-0,50+0,25$ and $-0,250+0,125 \mathrm{~mm})$ availability of TV glass concentration will have a limiting influence during thermal treatment.At waste glass concentration of $40+\%$ a deformation of compacts occurs and at synthesis temperature $\geq$ $1000^{\circ} \mathrm{C}(40 \% \mathrm{TV}$-glass and slag particles size $-1,0+0.5 \mathrm{~mm}$ or $-0.50+0.25 \mathrm{~mm}(-0.25+0.125$ $\mathrm{mm})$ the composites melt.

\begin{tabular}{|c|c|c|c|c|c|}
\hline Composite & $\mathrm{T},{ }^{\circ} \mathrm{C}$ & $\rho, \mathrm{g} / \mathrm{cm}^{3}$ & $\theta, \%$ & $\sigma, \mathrm{MPa}$ & $\mathrm{E}, \mathrm{GPa}$ \\
\hline Slag-M $(-1,0+0,5 \mathrm{~mm})+40 \%$ TV-glass & 950 & 2,23 & 31,60 & 25,07 & 16,87 \\
\hline Slag-M $(-0,50+0, .25 \mathrm{~mm})+40 \%$ TV-glass & 950 & 2,25 & 30,98 & 33,70 & 21,82 \\
\hline Slag-M $(-0,250+0,125 \mathrm{~mm})+40 \%$ TV-glass & 950 & 2,29 & 29,75 & 40,88 & 25,68 \\
\hline
\end{tabular}

Table 6. Density, porosity and mechanical characteristics of double layered Slag-M+TV-glass composites

The composite Slag-M+40 \% TV-glass (Table 6), sintered at $950^{\circ} \mathrm{C} / 2 \mathrm{~h}$ is suitable for practical application. It has porosity of $29,75-30,98 \%$ and possesses the best mechanical properties $(\sigma=40,88-33,70 \mathrm{MPa} ; \mathrm{E}=25,68-21,82 \mathrm{GPa})$. The upper layer of this double layered composite, formed by the larger particles fraction, has porosity of $30-40 \%$ and pores size of $350-500 \mu \mathrm{m}$. The pores of the lower layer are with significantly smaller sizes - 50-100 $\mu \mathrm{m}$ and the integrated porosity is $29-31 \%$ (Vassilev et al., 2007b).

\subsubsection{Porous composites with gradient (multilayer) structure formed with carbon and coarse-grained slag}

The composite is formed by two layers with different integrated porosity, size, shape and orientation of the pores. The particles of the glass and the slag in the first layer are with sizes $<45 \mu \mathrm{m}$. Carbon dust $(3,5,7$ or $10 \%)$ with particles sizes $<1 \mu \mathrm{m}$ is used as pore-creator. Slag grains in the IId layer are with size $-1,0+0,5 \mathrm{~mm},-0,50+0,25 \mathrm{~mm}$ or $-0,250+0.125 \mathrm{~mm}$ and these of the glass are $<45 \mu \mathrm{m}$.

Compacts are pressed at pressure of 50,100, 150 and $200 \mathrm{MPa}$. and sintering is carried out at $\mathrm{T}=950^{\circ} \mathrm{C} / 2 \mathrm{~h}$; air atmosphere, heating rate of $5^{\circ} \mathrm{C} / \mathrm{min} . \mathrm{CO}_{2}$ produced during thermal treatment creates pores which determines high integrated porosity: I-layer - 35-40\% and IIlayer $-30-40 \%$. The relationship between the porosity $(\theta)$ of the composite's upper layer, formed by the pore-creator (carbon dust) and its percentage $(x)$ is described by the expression: $\theta=28,26 \exp (0,033 \mathrm{x})$. Lower layer porosity (at $\mathrm{x}=0)$ is $28,26 \%$.

Diffusers for waste water aeration can be produced from the porous composites which are thermodynamically stable and possess good mechanical characteristics, interconnected porous structure and chemical inertness in aggressive media. The low concentration of carbon dust ( $\leq 3-5 \%)$ guarantees air bubbles with smaller sizes (Vassilev et al., 2007b).

\subsection{About a possibility for application of metallurgical slag and waste glass 2.5.1 Obtaining of composites with controlled porosity}

The possibility for application of glass-ceramic composite based on metallurgical slag and waste glass with controlled porous structure as diffuser for water aeration is examined by Fidancevska et al. (Fidancevska et al., 2009). 
Permeability of the porous matrix is determined by measurement of the gas bubbles pressure through the porous medium and the resulting gas flow rate

For lowering of the temperature interval of the composites sintering waste glass from TV monitors was used. For obtaining of composites with high mechanical indices, Slag- $\mathrm{R}$ (fraction $-0,125+0,063 \mathrm{~mm}$ ) and concentration of the TV-glass $20 \%$ with particles size $<0,045$ $\mathrm{mm}$. The sintering temperatures $\left(\mathrm{T}_{\mathrm{s}}\right)$ and the main properties of the compacts are shown in Table 7.

\begin{tabular}{|l|c|c|c|c|c|}
\hline Composite & $\mathrm{T}_{\mathrm{s}}{ }^{\circ} \mathrm{C}$ & $\rho, \mathrm{g}^{\mathrm{c}} \mathrm{cm}^{-3}$ & $\theta, \%$ & $\mathrm{E}, \mathrm{GPa}$ & $\sigma, \mathrm{MPa}$ \\
\hline Slag-R $(-0,125+0,063 \mathrm{~mm})+20 \%$ TV-glass & 850 & 2,24 & 43 & 9,6 & 36 \\
\hline Slag-R $(-0,125+0,063 \mathrm{~mm})+20 \%$ TV-glass & 900 & 2,25 & 42 & 10,0 & 39 \\
\hline Slag-R $(-0,125+0,063 \mathrm{~mm})+20 \%$ TV-glass & 950 & 2,26 & 43 & 11,0 & 41 \\
\hline Slag-R $(-0,125+0,063 \mathrm{~mm})+20 \%$ TV-glass & 1000 & 2,28 & 45 & 9,9 & 38 \\
\hline
\end{tabular}

Table 7. Sintering temperature $\left(T_{s}\right)$, density $(\rho)$, porosity $(\theta)$, elasticity modulus $(E)$ and bending strength $(\sigma)$ of composite Slag-R+TV-glass

The composite Slag-R(-0,125+0,063 mm) $+20 \%$ TV-glass (sintered at $950{ }^{\circ} \mathrm{C} / 2 \mathrm{~h}$ ) has optimal properties (Table 7) and the technical coefficient of linear thermal expansion $\left(\alpha_{\text {tech }}\right)$ of this composite is within the interval $20-600^{\circ} \mathrm{C}$ is $10,9.10^{-6}{ }^{\circ} \mathrm{C}^{-1}$.

This composite is used for the following experiments. Its SEM-microphotography is shown on Fig. 1.

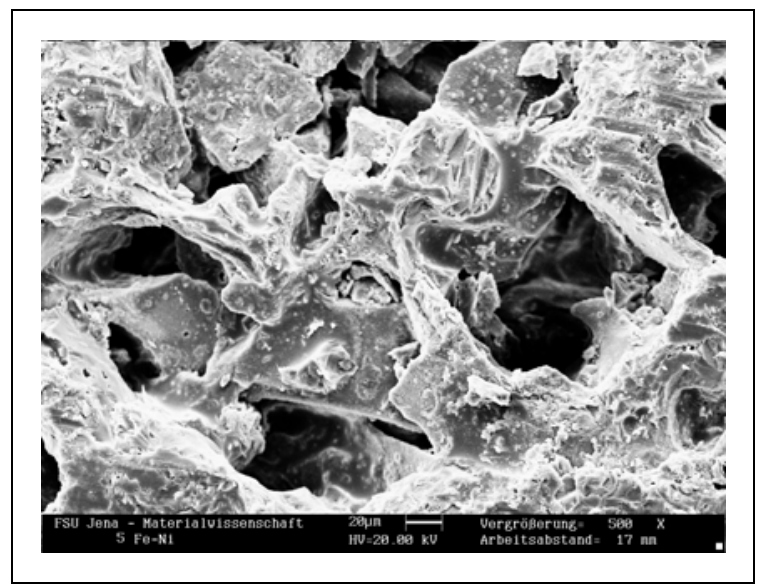

Fig. 1. SEM micrograph of the composite Slag-R(-0,125+0,063 mm) + $20 \%$ TV-glass, sintered at $950^{\circ} \mathrm{C} / 2 \mathrm{~h},($ bar $20 \mu \mathrm{m})$

The integrated porosity of the obtained composite is $43 \%$. Micropores of closed type with sizes of 5-10 $\mu \mathrm{m}$ are present in the composite as well as opened pores with sizes of 250-500 $\mu \mathrm{m}$ connected with the voids between the slag's grains and soldered with the glassy phase. Fractures among the pore walls were not evident.

Stability tests of the same composite in $0,1 \mathrm{M} \mathrm{HCl}$ and in $1 \mathrm{M} \mathrm{Na}_{2} \mathrm{CO}_{3}$ show that the weight loss after 24, 168 and $720 \mathrm{~h}$ varies between 0,02 and 0,6 wt. \%, i.e. the composite is stable in aggressive media (Fidancevska et al., 2009). 


\subsubsection{Diffuser for water aeration}

The permeability of the porous matrix is one of the most important characteristics determining its possible application. Pressure drop through the composite Slag-R $(-0,125+0,063 \mathrm{~mm})+20 \mathrm{wt}$. \% TV-glass as a function of the volumetric flow rate per unit of cross sectional area is shown in Fig. 2.

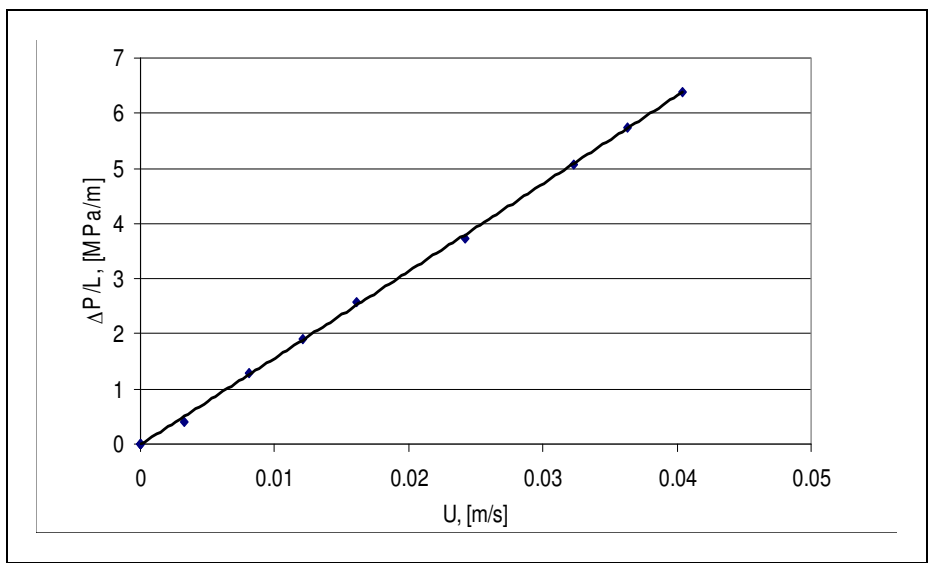

Fig. 2. Dependence of the volumetric flow rate per cross sectional area unit on the air pressure drop

Air permeability through the porous medium and the shape coefficient of the porous composite Slag-R $(-0,125+0,063 \mathrm{~mm})+20 \%$ TV-glass are $\mathrm{K}_{\mathrm{o}}=0,42 \mathrm{Da}\left(1 \mathrm{Da}=0,987.10^{-12} \mathrm{~m}^{2}\right)$ and $\mathrm{C}_{\mathrm{o}}=5,82.10^{6} \mathrm{~m}^{-1}$, respectively. The mean cross sectional Darcy rate of the fluid, when the flow changes from Darcy's to quadratic flow regime, is $4,3 \mathrm{~m} / \mathrm{s}$.

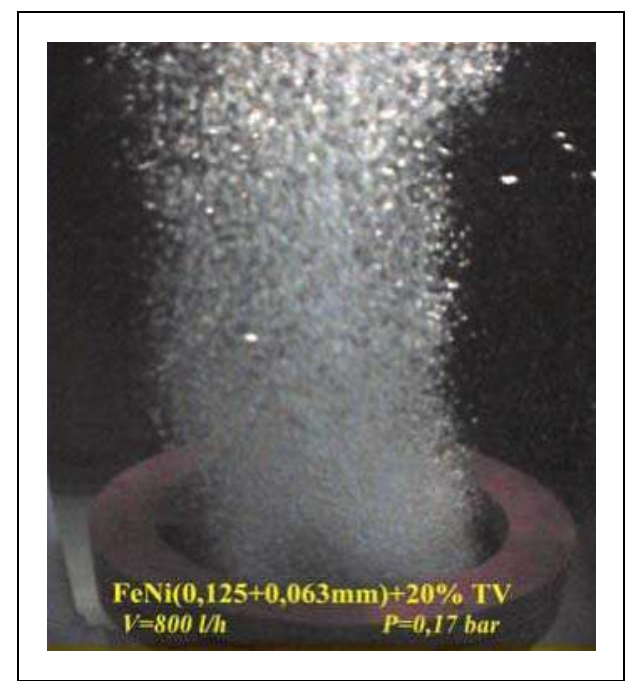

Fig. 3. Diffuser for water aeration (air flow $\mathrm{V}=800 \mathrm{l} / \mathrm{h}$, air pressure $\mathrm{P}=0,17 \mathrm{bar}$ ) 
This composite with controlled porosity is used for construction of diffuser for water aeration. The composite Slag-R $(-0,125+0,063 \mathrm{~mm})+20 \mathrm{wt}$. \% TV-glass is built in plastic polyamide holders supplied with gaskets and inlet for air feeding. The diffuser has the following dimensions: $\varnothing=30 \mathrm{~cm} ; \mathrm{h}=6 \mathrm{~cm}$. It is tested with working liquid water. Air flow is changed between $2.10^{-3}-7.10^{-2} \mathrm{~m}^{3} /\left(\mathrm{m}^{2} . \mathrm{s}\right)$ and the air pressure - from 0,05 to $1,00 \mathrm{bar}$ (Fig. 3).

The size of air bubbles depends on the air pressure in the aerator as the finest bubbles are obtained at low air pressure: at 0,05 bar their diameter is $300 \pm 100 \mu \mathrm{m}$. When the air pressure is increased up to 0,1 bar their diameter becomes 1,5-2,0 mm. A partial junction of bubbles is observed during their appearance from the diffuser's pores. At air pressure of 0,2 bar their diameter slightly increases and is about $2,5 \pm 0,5 \mathrm{~mm}$. At pressure of 0,3 bar the bubbles change their geometry and possess diameter of $4 \pm 1 \mathrm{~mm}$, which at 1 bar pressure reaches sizes $5 \pm 1 \mathrm{~mm}$ as a result of their instantaneous coalescence.

The diffusion air compression on the diffuser, the bubbles size, the air pressure, etc., show that the investigated composites based on industrial wastes (FeNi-Slag and TV-glass) can be used as diffusers for water aeration (Fidancevska et al., 2009).

\section{Organic composite materials containing waste}

\subsection{Polymer composites containing organic waste}

\subsubsection{Polymer composites containing waste rubber}

Although rubber wastes constitute a small portion of all world solid waste, their overall amount steadily increases as the number of disposed worn out tyres grows. For many years incineration and landfill were and, in some parts of the world, still are the main methods of their disposal. In the last years the rubber waste is applied in pavement of roads (Khalid \& Artamendi, 2004), in the production of asphalt concrete mixtures (Tunsan, 2003; Zhan Ding et al., 2010), for production of activated carbons (Ko et al., 2004) but mostly as a fuel in cement production factories and kilns. Last few years waste rubber and mainly scrap tires were considered as one of the alternative energy sources (Stelmachowski \& Słowiński, 2009, 2010). In addition grinded rubber waste and obtained granulate, fine rubber particles or rubber dust offer possibility for production of new composite materials with valuable properties - in (Aules, 2011; Sathiyamoorthy et al., 2011), for concretes with enhanced thermal insulation properties (Siddique\& Naik, 2004; Yesilata et al., 2009), for sound insulation materials (Asdrubali, 2006) etc.

With regard to what has been said so far this topic of investigation combines naturally low thermal and electrical conductivity of UP in combination with rubber particles as a filler to find a way for waste rubber utilization as a component of polymer composites with electrical-, thermal- and sound insulation properties.

Experimental composites are based on unsaturated polyester resin (UP) "Vinalkid 550 $\mathrm{P}^{\prime \prime}($ Orgachim Ltd, Bulgaria). The commercial product was a $66.8 \mathrm{w}$. \% solution of the base polyester in styrene and was used as supplied by the producer. Polyester solidification was performed with cyclohexanon peroxide as initiator and cobalt-naphtenate as accelerator both in concentration $2 \mathrm{w}$. \% related to the UP weight. Rubber particles from ground rubber waste, $0.2-0.4 \mathrm{~mm}$ of size, previously dried are used as filler. Maximum concentration of the filler was determined as $12 \mathrm{w}$. \% because of the sharp rise of viscosity at higher waste concentration. 
Simple blending technology was used to prepare experimental samples: the resin and rubber particles were mixed thoroughly using a high-speed stirrer (700 rpm), cast in open polypropylene moulds and then cured at room temperature for $24 \mathrm{~h}$. Post curing at $80^{\circ} \mathrm{C}$ for $2 \mathrm{~h}$ was further applied.

In order to specify processing parameters flow behavior of UP/rubber particles polymer system was studied using rotational viscosimeter RHEOTEST (Germany), measuring device "cylinder - cylinder" (shear rate $0.2-1.310^{3} \mathrm{~s}^{-1}$, temperature range $25-85^{\circ} \mathrm{C}$ ). Rheological experiments showed that "UP/rubber particles" polymer system could be characterized as suspensions of solid particles in Newtonian liquid. According to Utracki (Covas et al.,1995) the most common type of flow for suspensions is pseudoplastic, characterized by upper $\left(\eta_{0}\right)$ and lower $\left(\eta_{\infty}\right)$ Newtonian viscosity. Results obtained by measurements confirmed that the presence of rubber particles changes the rheological behavior of the UP, depending on the rubber content from Newtonian at low concentrations, to dilatant at $10 \mathrm{w}$. $\%$ and pseudoplastic at $12 \mathrm{w} . \%$ (Fig.4).

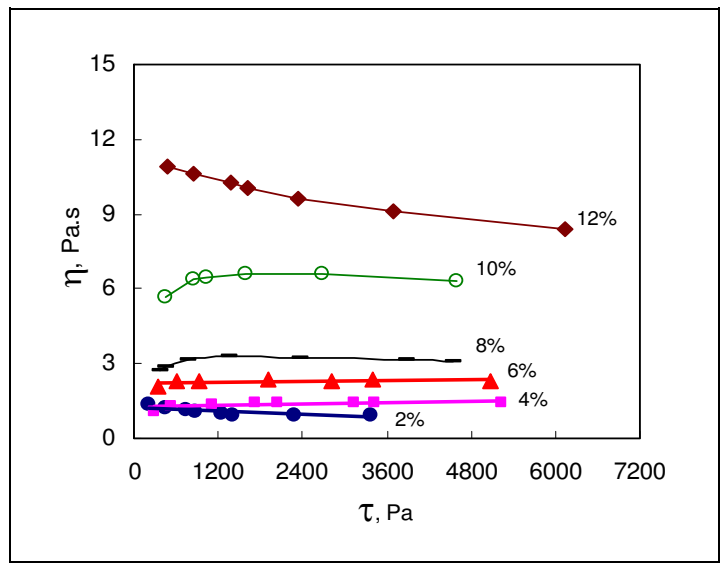

Fig. 4. Viscosity $(\eta)$ - shear stress $(\tau)$ dependence for $U P /$ rubber particles suspension $\left(t=25^{\circ} \mathrm{C}\right)$

The possible reason for system flow behavior peculiarities was investigated applying optical microscopy (magnification x100). Rubber particles' optical micrographs demonstrated a very irregular shape and high-developed particles surface. Perhaps the close contacts between rubber particles at high concentration create a specific structure like pseudo-set and in this way the polyester resin turns out immobilized. Because of the highly developed particles' surface the quantity of the resin at $12 \mathrm{w}$. \% rubber concentration is not enough to fully wet the filler and there is not really existing inter-phase layer between the two phases. It is known that the thickness of this layer is in high degree responsible for mechanical and strength properties of the composite. Based on these results, rubber particles content was limited up to $10 \mathrm{w}$. \%.

As chemically inert composite component rubber particles were expected to not influence chemically the polyester curing reaction. The influence of the rubber particles on the process of solidification and mechanical behaviour of the composition were studied by mechanical impedance measurement on liquid-state samples (Petkov et al., 1999). The change of the mechanical impedance during the chemical solidification process follows the usual S-shaped 
line (Fig. 5) but the increasing amount of waste particles leads to slow down of the curing reaction.

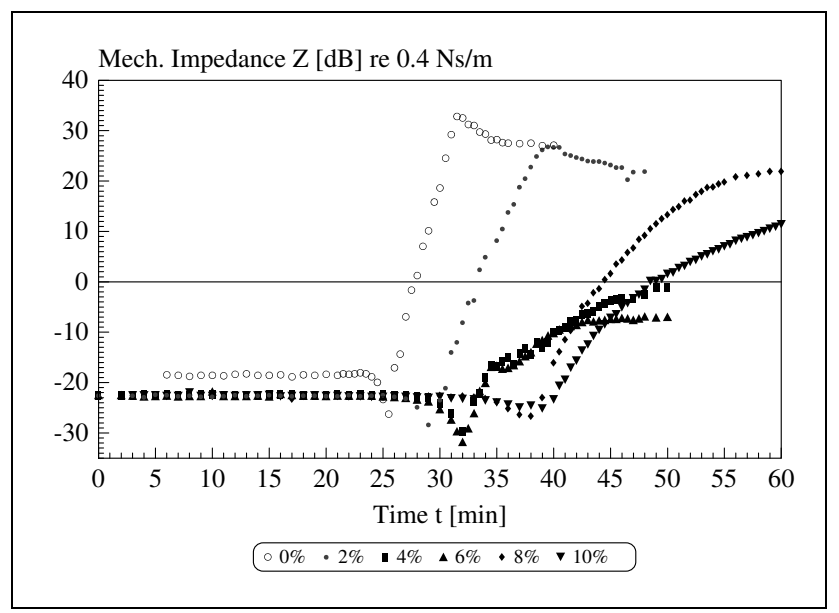

Fig. 5. Summarized plot of the experimental results for the mechanical impedance $Z$ vs. the time for different concentration (w.\%) of rubber particles

Strength properties of the polymer composite as impact strength, tensile breaking strength, compressing and bending strength were evaluated because these are the key properties most likely to be affected by incorporation of rubber particles. Experimental and measuring procedures are based on standard methods: Tensile strength at break was measured on ZD-20 all-purpose testing machine on standard dumbbell - shaped specimens, cut from $2 \mathrm{~mm}$ thick sheet, at room temperature, $100 \mathrm{~mm} / \mathrm{min}$ speed; Charpy impact tests were carried out on notched specimens (pendulum power of $1.0 \mathrm{~J}$, span of $40 \mathrm{~mm}$ ); Bending and compressing tests were performed on universal ZD 10/90 testing machine, at $0,2 \mathrm{~mm} / \mathrm{s}$ plates moving rate, at room temperature (accuracy $\pm 1 \%$ ) (Koleva, 2005).

Experimental results showed that tensile strength at break, bending strength and compression strength decrease with the rubber content increasing. This effect could be logically explained having in mind the structure peculiarities mentioned above. Because of the close interaction and aggregation at low concentrations, rubber particles act more like "defects" than as a toughening agent and increase the defectiveness of the matrix. At higher rubber concentration the effect of high developed particles surface and, as a result of that, pure wetting also takes place. The negative effects of the particles shape on the flow behavior and strength characteristic of composite could be eliminated in high degree by using rubber particles obtained by cryogenic grinding - in this case particles are geometrically shaped, with well formed sharp edges. Thus the particles' aggregation could be avoided and composite properties could be significantly improved (Rodriguez, 1998).

Based on the analysis of flow behavior and composite strength properties the content of rubber waste in the further experimental work was limited to $10 \mathrm{w}$. \%. It was concluded also that the possible application of studied polymer composites should be limited for products, working in conditions without loading because of their insufficient strength characteristics. Thermo-physical characteristics of the composites were performed on ALAMBETA 
measuring device (Czech Republic) at $25 \pm 1^{\circ} \mathrm{C}$. Thermal conductivity $\lambda$, thermal absorption $b$, thermal resistance $r$ and thermal diffusivity coefficient $a$ were calculated (Koleva et al., 2003).

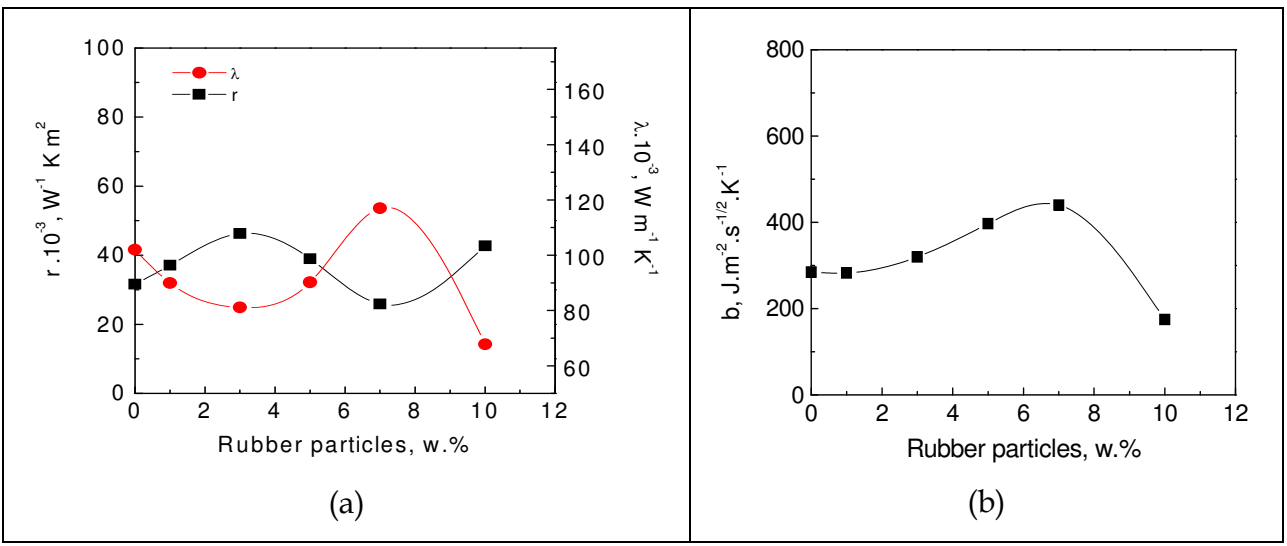

Fig. 6 . Thermal conductivity $(\lambda)$, thermal resistance $(r)$ and thermal absorption (b) vs. rubber particles concentration, $w . \%$

Data collected from experiments showed that the rubber particles content influences thermo-physical properties of the composition decreasing the thermal conductivity (Fig.6a) and increasing respectively the thermal resistance and thermal absorption of studied compositions (Fig.6b). An opposite tendency marks the changing of thermal absorption coefficient. The composition with $7 \mathrm{w}$. \% shows lowest thermal conductivity and thermal diffusivity, and at the same time - high thermal absorption, therefore, it is suitable for thermal isolation materials.

When studying the electric characteristics of polymer materials two groups of properties are of great interest: the properties specified by the polymer characteristics in weak electric fields (dielectric permeability, tangent of dielectric losses, electrical conductivity) and those specified in strong electric fields (breakdown voltage, durability). The properties of the first group are closely related to the polymer chemical composition and structure. The evaluation of the second group is influenced by the presence of polar or non-polar ingredients as well as by the methods used for determining these properties.

RLC bridge and brass electrodes are used to measure the relative dielectric permeability $\left(\varepsilon_{\mathrm{r}}\right)$ and the tangent of the dielectric losses angle $(\operatorname{tg} \delta)$, at $1 \mathrm{kHz}$ frequency and room temperature. The dependences of these quantities on the frequency are determined by means of a Q-meter and by using a resonance method within the $8-25 \mathrm{MHz}$ frequency range. A terra-ohmmeter was used for the specific volume resistance measurements at room temperature. To measure the electric strength high-voltage devices AII-70 at a constant rate of voltage increase are used.

Dependences of the dielectric permeability $\varepsilon_{\mathrm{r}}$ and dielectric losses tg $\delta$ on the rubber content are similar as a trend. The more considerable change in the tg $\delta$ values could be explained with the presence of electric conductivity losses. Frequency dependence of $\varepsilon_{\mathrm{r}}$ showed well expressed dispersion of values at the resonance frequencies - at high waste amounts new maximum values due to the rubber polarization occur (Fig. 7a). The tangent of the dielectric 
losses angle decreases when the frequency increases for all materials studied since electric conductivity losses and polarization losses decrease (Fig. 7b). The highest tg $\delta$ values observed at frequency $9 \mathrm{MHz}$ are due to resonance losses and they are more considerable at higher waste content. The specific volume resistance decreases with increasing the rubber content. The values of the electric strength are commensurate with those of the pure unsaturated polyester resins.

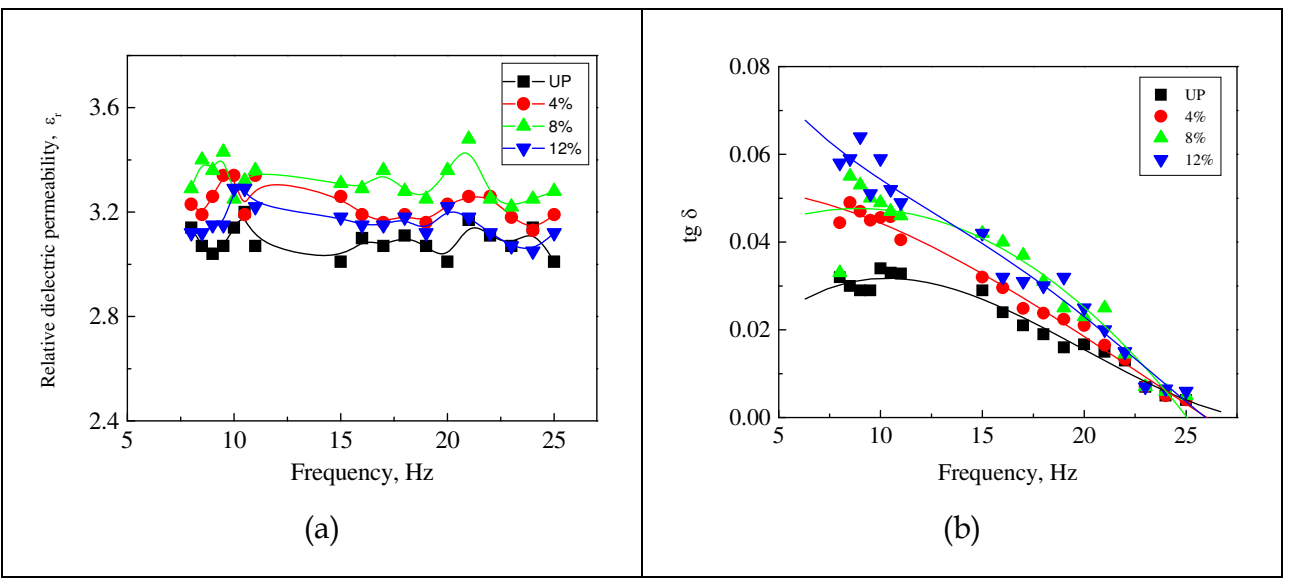

Fig. 7. Frequency dependence of the relative dielectric permeability (a) and $\operatorname{tg} \delta(b)$ at various rubber contents

It was found by preliminary studies that the composition containing waste rubber particles demonstrates a good combination of elastic and viscose properties (Petkov et al., 1999). That offers possibilities for utilising the composition studied as a vibration dumping material.

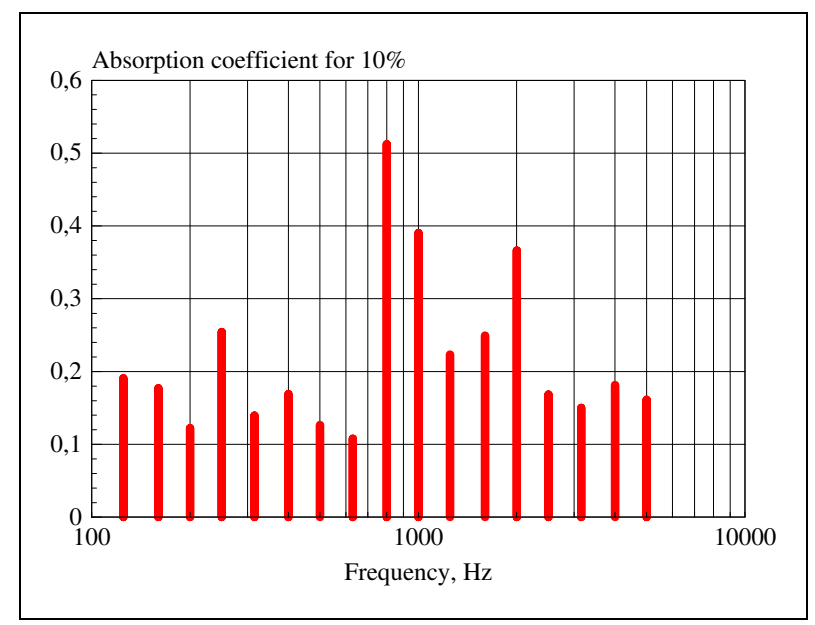

Fig. 8. Absorption coefficient $\alpha$ vs. frequency in $1 / 3$ octave intervals for $10 \mathrm{wt}$. $\%$ rubber particles concentration 
For estimation of the sound absorption properties of the composition a standard standing wave method was applied (Heckl \& Mueller, 1995). The method is based on sound pressure level measurement in a tube of Kundt. As a result two parameters were calculated: acoustic impermeability $R$ and absorption coefficient $\alpha$ (Petkov et al., 2001). The values of the absorption coefficient were measured for all 1/3 octave frequency bands in the range 125 $5000 \mathrm{~Hz}$ (Fig.8). It is known that the frequency of $1000 \mathrm{~Hz}$ is a $0 \mathrm{~dB}$ level in the $\mathrm{dB}$ (A)weighting filtering characteristics i.e. the isolation materials frequency response is supposed to be invers. Interesting results were obtained for the composition containing $10 \mathrm{wt}$. \% of waste in the whole investigated frequency range, with very high values of absorption coefficient $(\alpha>0.5)$ around $800-1000 \mathrm{~Hz}$. The same composition shows also very high stability and repeatability of results obtained by preliminary held experiments. The obtained high values for the absorption coefficient $\alpha$, offer possibilities for practical application of the composite as an acoustical isolation material $(\alpha>0,5)$.

\subsubsection{Polymer composites containing Gypsum-fiber waste}

In the production of gypsum-fiber boards, gypsum-fiber powder is obtained as waste material. The usage of both gypsum and fiber as fillers of polymer composite materials is well known. The usage of waste material as a component of a composite material results in reduction of its cost, and in a positive environmental effect in view of the ecological problems (Pemikis, 1998; Zheglova, 2001).

Composite materials based on unsaturated polyester resin and epoxy resin as matrix and waste gypsum-fiber power - technological scrap as filler were studied in order to their possible application for electric insulation materials. The composites based on UP-PS5323 resin were solidified using iniciator Arrcoper 20 and Pitt-Consol 640 accelerator. The gypsum-fiber powder is processed up to $50^{\circ} \mathrm{C}$ within 10 hours, to remov the absorbed moisture. Simple blending technology, described above was used to prepare the experimental samples. The maximum quantity of gypsum-fiber powder has been defined to not exceed $40 \mathrm{w}$. \% (Zheglova\& Rashev, 2003).

Physical characteristics of the obtained composite material as density and hardness, strength and electric properties were measured as a function of the filler content. It was established that by increasing the filler quantity in the composition the composite density (Fig. 9a) and the hardness (measured with Brinell methods) (Fig. 9b) increased.

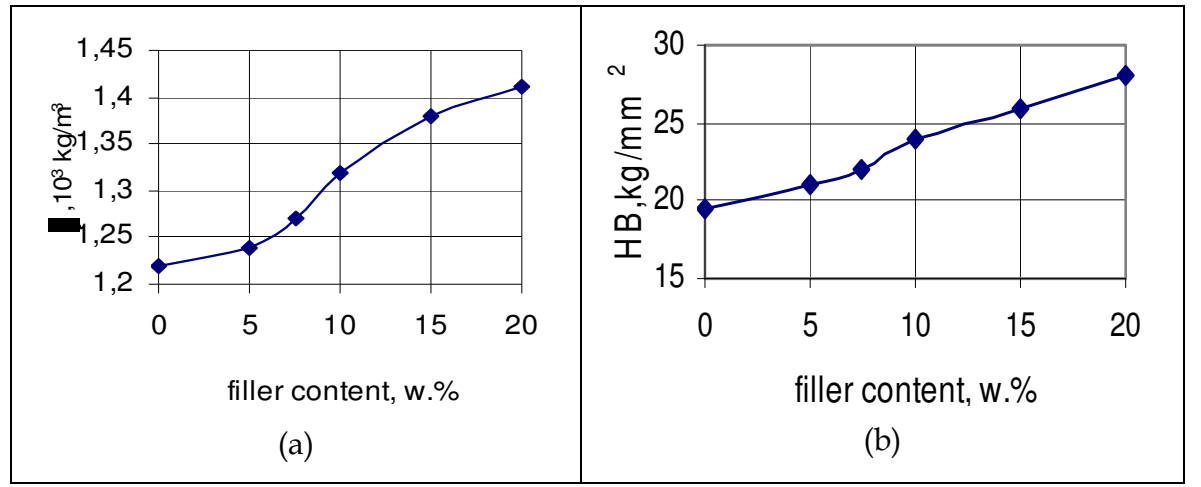

Fig. 9. Dependence of the composite density (a) and hardness (b) on the quantity of gypsumfiber waste for UP-based composites 
Strength characteristics of the composition also depend on the filler's amount in the composition. When the filler content increases, both tensile and compressive strengths decrease sharply at contents up to 7 (Fig. 10). The impact strength increases for composites containing up to $10 \%$, then it gradually decreases while the gypsum-fiber content increases.

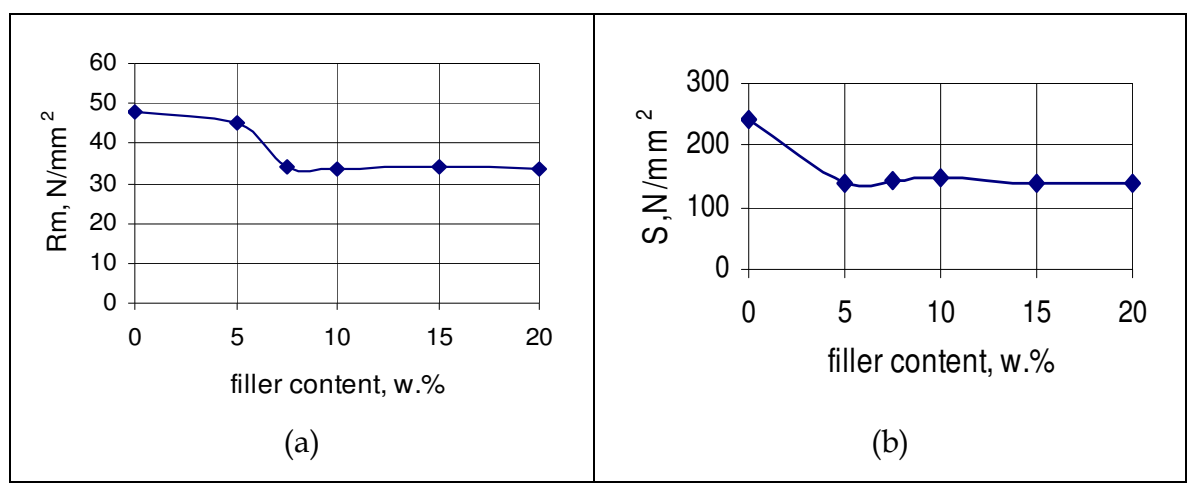

Fig. 10. Dependence of the composite tensile strength $\mathrm{R}(\mathrm{a})$ and compressive strength (b) on the gypsum-fiber concentration, $\mathrm{w} . \%$ for composite based on UP

These trends considering the composite strength characteristics should be related first to the properties of its components (polyester resin and gypsum-fiber powder) on the one hand, and to the intensity of adhesion between the two phases on the other. The presence of microscopic particles of gypsum-fiber powder hinders the development of the dislocation planes of skidding in the process of determination and research of strength characteristics, influencing the process of destruction of the sample bodies (Zheglova\& Rashev, 2003).

The influence of filler's amount on the electric properties of the composition as relative dielectric permeability $\varepsilon_{\mathrm{r}}$ and $\operatorname{tg} \delta$ was studied. The relative dielectric permeability of complex dielectrics, which are compounds of chemically non-interacting components of different permeability values and with chaotic distribution of the components, as is the case with the composite materials under investigation, may be approximately described by the Lichtenekker equation (Pasinkov, 1986).

$$
\ln \varepsilon_{\mathrm{r}}^{\mathrm{x}}=\theta_{1} \ln \varepsilon_{\mathrm{r} 1}^{\mathrm{x}}+\theta_{2} \ln \varepsilon_{\mathrm{r} 2}{ }^{\mathrm{x}}
$$

Using this equation (1), the values of $\varepsilon_{\mathrm{r}}$ of the obtained materials are calculated and compared with the experimentally measured values of $\varepsilon_{\mathrm{r}}$ for frequencies of $1 \mathrm{kHz}$ and $10 \mathrm{MHz}$ (Fig. 11).

A certain difference is observed between the calculated and measured values, but that is due to the fact that the composite material is assumed to consist of resin and filler only. In reality, it contains a small amount of gas inclusions in which moisture with great relaxation polarizations permeates.

Increasing the gypsum-fiber contents leads to increase of $\operatorname{tg} \delta$ as the gypsum-fiber has greater losses due to both polarizations and conductivity. When the frequency increases, $\operatorname{tg} \delta$ decreases because the slow polarizations disappear (Pasinkov, 1986; Zheglova, 2002).

The composite materials based on epoxy resins and gypsum-fiber were produced the same way as those based on UP and gypsum-fiber, using DER 331 epoxy resin (USA) with accelerator BDMA (Ciba-Switzerland) and hardener HY 917. 


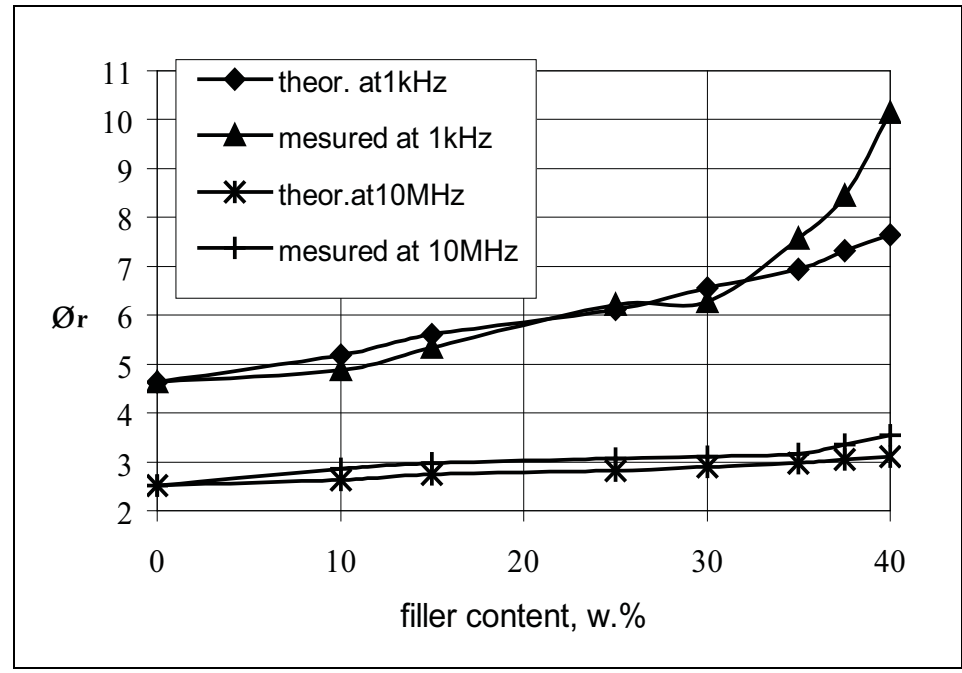

Fig. 11. Dependence of the composite relative dielectric permeability on the gypsum-fiber concentration

When comparing the properties of the composite materials with a gypsum-fiber filler based on unsaturated polyester resins and those of the materials based on epoxy resins, it could be concluded that the epoxy composite has a lower density and a hardness, but have a higher compressive strength (Fig. 12a), and impact strength (Fig. 12b).

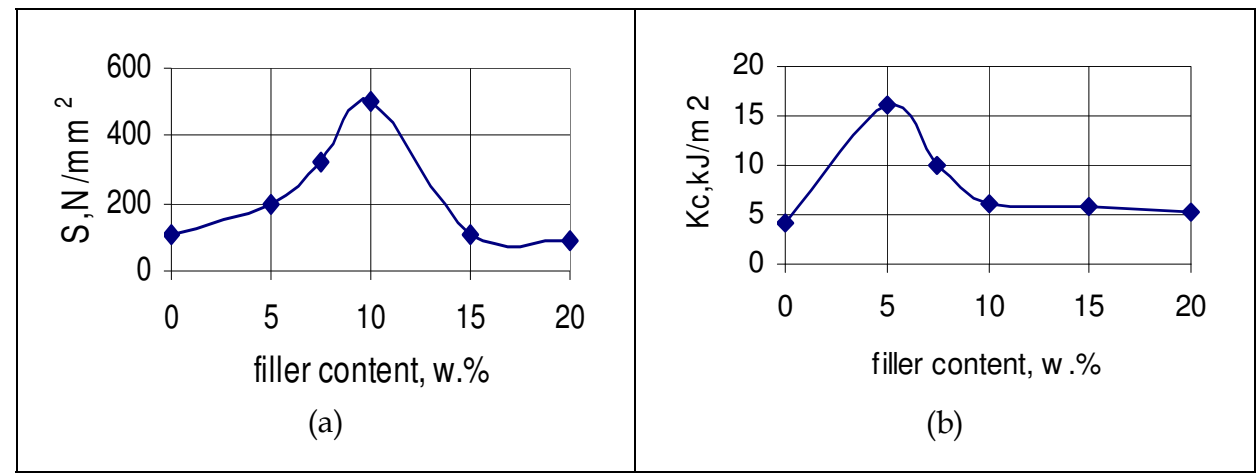

Fig. 12. Strength characteristics of epoxy resin-based composite containing gypsum-fiber waste as a function of the waste content: (a) compressive strength; (b) impact strength

The values of the tangent of the dielectric losses angle are comparable, but their dielectric permeability is lower due to their lower density. The electrical strength of the materials based on epoxy resins increases (Fig. 13a) when the quantity of the filler increases, whereas the electrical strength of the materials based on unsaturated polyester resins decreases under the same conditions (Fig. 13b).

Despite all this, all analyzed materials based on epoxy resins have a higher electrical strength than the materials based on unsaturated polyester resins. (Zheglova \& Rashev, 2002). 


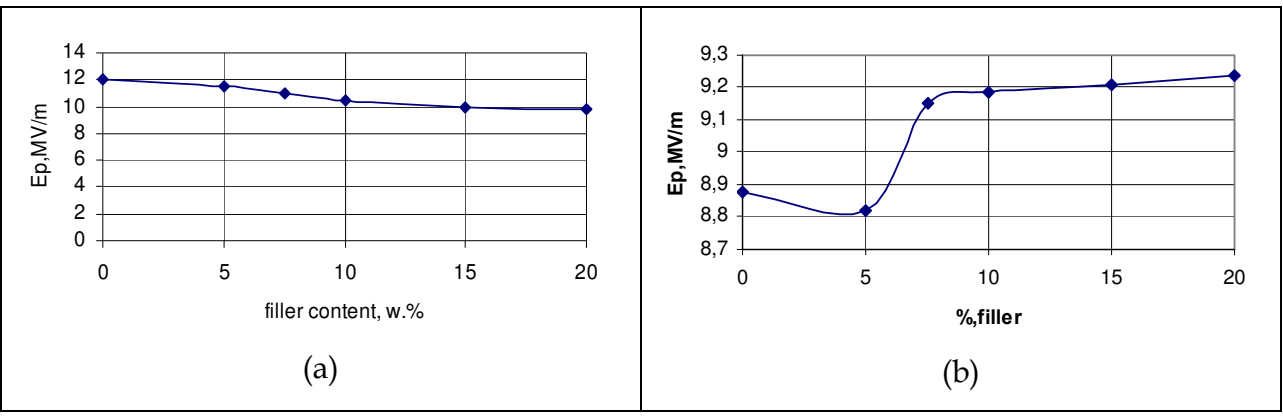

Fig. 13. Dependence of the electric strength on the gypsum-fiber quantity: (a) for UP - based composites; (b) for epoxy- based composites

\subsection{Polymer composites containing inorganic waste}

\subsubsection{Organic composites containing waste dust from power production}

Producing energy from coal and oil releases a wide range of pollutants into the environment. Moreover generation of sulphuric dioxide and nitrogen oxides, power production industry is one of the main sources of particulate matter in the air - industrial combustion plants and processes (17\%), commercial and residential combustion (16\%) and public power generation $(15 \%)$.

Ion based or electric filters are used to trap solid particles emission produced by burning in furnaces. Dust accumulated in these filters is deposited at dump sites. However, the chemical composition of captured electric filter dust is in fact a mixture of mineral oxides which could be used as fillers in both organic or inorganic composites intended for various applications. In this connection there has been studied the possibility of using waste dust from electric filters as filler in polymer compositions featuring electric insulation properties. Unsaturated polyester resin "Vinalkid 550 PE - R" (Orgahim, Bulgaria) was used as matrix for the polymer composition. Waste dust collected by electro filters of thermal power station Maritza-Iztok 2 (Bulgaria) was used as filler. The filler was first fractionated - the largest fraction obtained after $t$ fractioning was defined to be $125-250 \mu \mathrm{m}$. Following fractionating the waste has been processed by three consequent thermal processes: at 110,600 and $800{ }^{\circ} \mathrm{C}$ until constant weight has been reached. Waste chemical composition was determined by combination of classical silicate analysis and atomic-absorption spectroscopy. Chemical analysis showed that it is composed by mixture of oxides, among them more than $50 \%$ is inert $\mathrm{SiO}_{2}$, followed by $\mathrm{Al}_{2} \mathrm{O}_{3}$, some quantity of ferrous oxide and some other oxides. The mixture also consists of heavy metals' oxides and alkaline oxides in traces.

X-ray diffraction analysis was also processed on DRON-3 automatic powder diffractometer using filtered $\mathrm{CuK} \alpha$ irradiation. The analysis showed the presence of the following phases (vol. \%): quartz - 35.68; CaAl2Si2O8 - 28.03; mullite (3Al2O3.2SiO2) - 25.95; magnetite (Fe3O4) - 7.06; cristobalite - 3.27 (Koleva et al., 2008a).

Waste has been dried in electrically heated in thermal camera at $80^{\circ} \mathrm{C}$ for 24 hours for the sake of removing absorbed moisture before using it in the polymer composition. The waste content in the composition was limited up to $25 \mathrm{w}$. \% as it was established that amounts greater than $25 \mathrm{w}$. \% bring to a sharp increase in the viscosity thereby deteriorating of composition processability. 
In order to investigate the influence of the waste on the composite's properties following composites were prepared and studied: composites containing mixed (not fractionated) not treated waste; composites containing activated waste with $125-250 \mu \mathrm{m}$ size of particles and composits based on modified with high impact polystyrene (HIPS) polyester resin containing mechanically activated waste with $125-250 \mu \mathrm{m}$ size of particles.

Strength and electrical characteristics of the material were tested to prove the suitability of experimental composites for electrical insulation materials. Strength characteristics as shockresistance, compressive strength, and bending strength were determined using standard techniques described above. (Koleva et al., 2007). Specific electrical characteristics of the material as relative dielectric permeability, tangent of dielectric losses angle, electric strength and specific volume resistance were tested by methods and measuring devices described earlier (Zheglova et al., 2007).

Results obtained by experiments for composites containing mixed (not fractionated) waste showed that the presence of waste influences the studied strength characteristics and this influence depends on the amount of the waste in the composition. Into the studied concentration range the waste lowers the impact strength up $20 \mathrm{w} . \%$ waste content - then the impact strength values increase but the processing properties become worse. The waste also causes a drop of bending and compressive strength values compared to the neat polyester resin (Koleva, 2007).

According to Lipatov (Lipatov, 1986) the possible reason for this negative effect could be the poor interaction between the composition components. The main way to improve the interaction between phases and thus to improve the properties of the composite is to modify the filler and/or the polymer matrix. Two approaches were experimented: waste mechanical activation and modifying of polyester with polymer additive.

Waste mechanical activation was performed by dry processing in ball crusher with agate balls at room temperature for 15, 30, 45, 60, 120 and 180 minutes. During the milling process the particles surface energy increases constantly, but in a certain moment the geometric factor of activity (the specific surface) starts to exert influence. From this moment on the specific surface decreases, so this corresponds to the optimal milling time. In this particular case the optimal results were obtained at milling time of 30 minutes. Following mechanical processing the waste was again fractioned and chemically tested to determine some possible changes in particle size and chemical composition.

Chemical tests did not show significant changes in the waste chemical composition as the waste treatment was purely physical. But some changes in particles' size distribution compared to the one before treatment were observed (Fig. 14) - the amount of particles with largest size above $500 \mu \mathrm{m}$ was reduced in half while the amount of the smallest particles (under $45 \mu \mathrm{m}$ ) doubled in the same time. The amount of $250-500 \mu \mathrm{m}$ fraction increased and those of 125 - $250 \mu \mathrm{m}$ decreased with one and the same amount so the quantities of two main fractions in the waste dust become almost equal. Decreasing in amount of largest particles and increasing the amount of smallest ones leads to more uniform and larger size distribution of waste particles so some changes in mechanical and strength properties of the studied composites could be expected (Koleva et al., 2008a).

Optical microscopy (magnification $\times 110$ ) was applied to evaluate possible changes in waste particle shape and surface after activation. The irregularly shaped waste particles become more regular and round after activation. This effect, combined with the effect of particles size changing, could be a prerequisite to enhance the interaction between the polymer and the filler and thus the composite strength characteristics. 


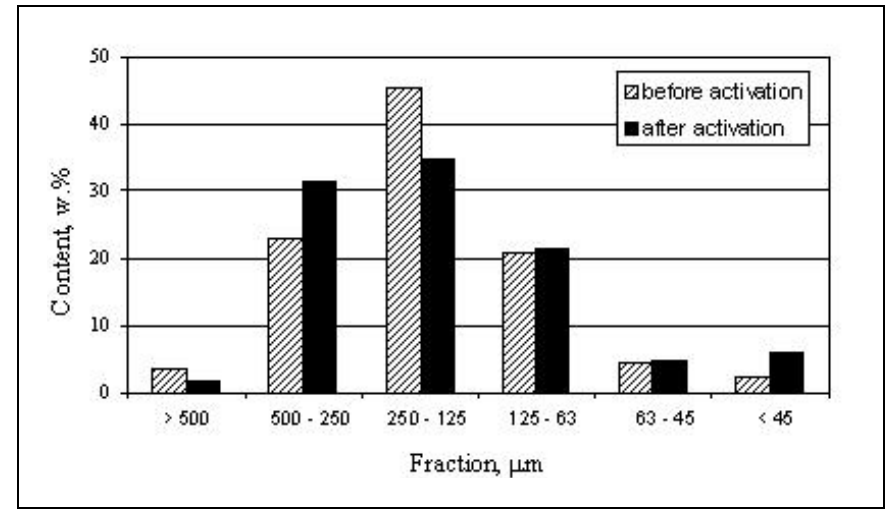

Fig. 14. Size distribution of waste dust particles before and after mechanical activation

Having in mind the effect of activation process on the size and shape of the waste, activated waste fraction 125 - $250 \mu \mathrm{m}$ was used in further experiments.

Based on the experimental results it could be concluded that the waste activation slightly influences the composite strength characteristics; in general, the type of the dependences does not change, but "activated" composites show higher bending and compressive strength (Fig. 15a and 15b) and lower impact strength compared to the "non- activated" ones (Koleva, 2008a, 2008b).

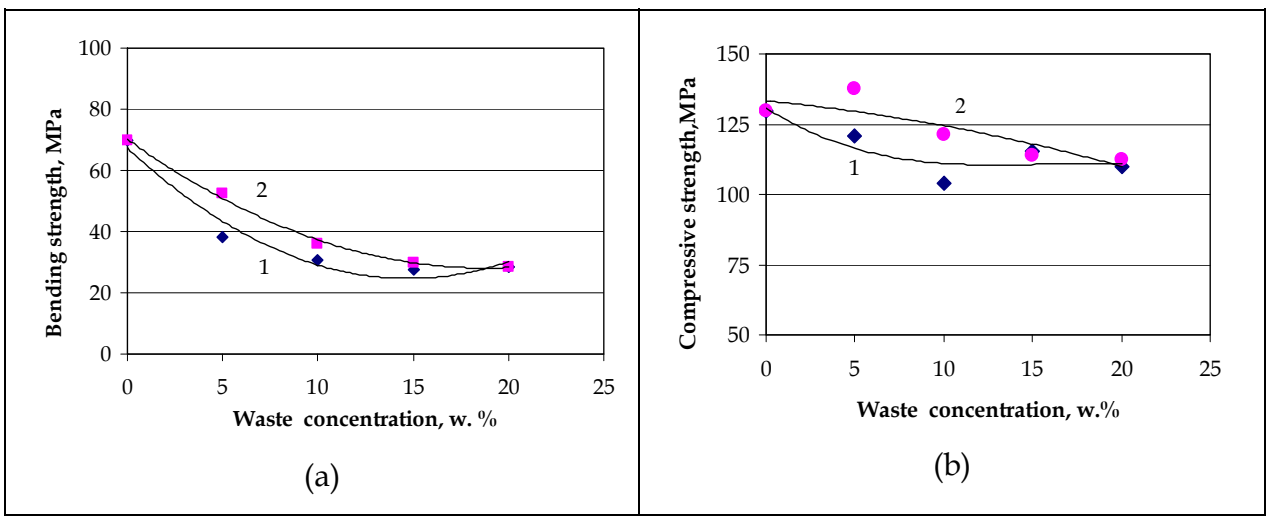

Fig. 15. Effect of waste dust content on bending (a) and compressive (b) strength of polymer composites containing not activated (1) and activated waste (2)

Electrical characteristics of the experimental composites were also influenced by waste mechanical activation. After the activation electrical strength increases and has its maximum at $10 \mathrm{w}$. \% of waste (Fig. 16a) most probably due to the more uniform shape and size of the waste particles. Relative dielectric permeability increases also because of the dropping out of slow polarizations (Fig. 16b). The effect of activation is more clearly expressed at high frequency because of the stronger interaction between the waste particles and the polymer after activation - due to reduced molecules' mobility their polarization in the electric field becomes more difficult. 
When the dielectric permeability decreases, $\operatorname{tg} \delta$ values increase (Fig.17a) - this is caused by the increment of conductivity losses. This effect was proved by the specific volume resistance values (Fig.17b), which are in greatest degree changed after the activation (Koleva et al., 2008c).

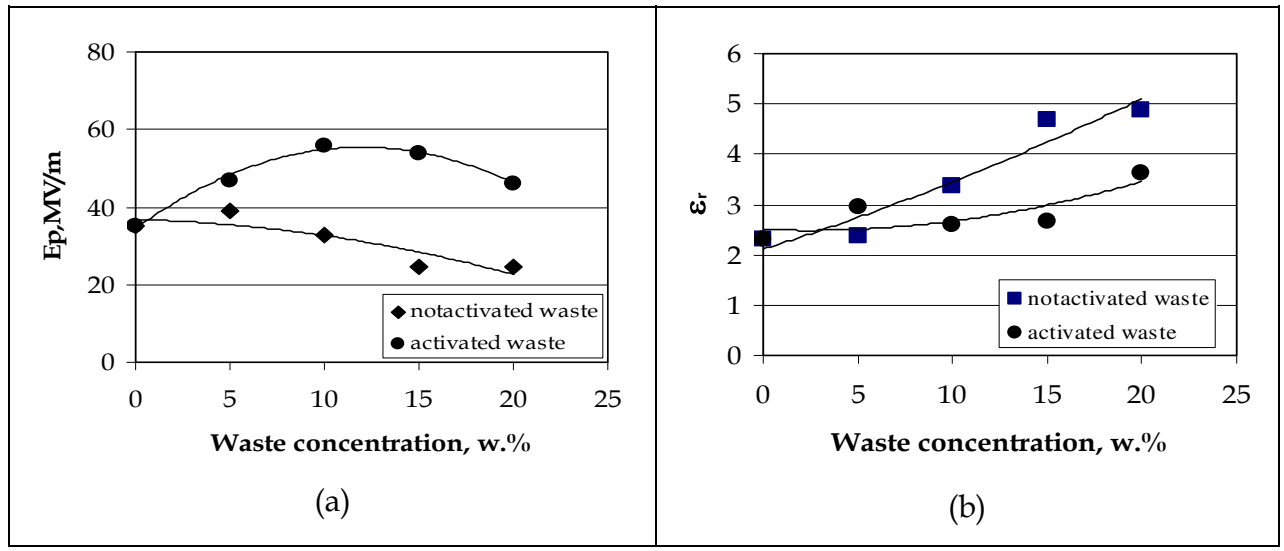

Fig. 16. Dependence of composite electrical strength (a) and relative dielectric permeability (b) on waste amount

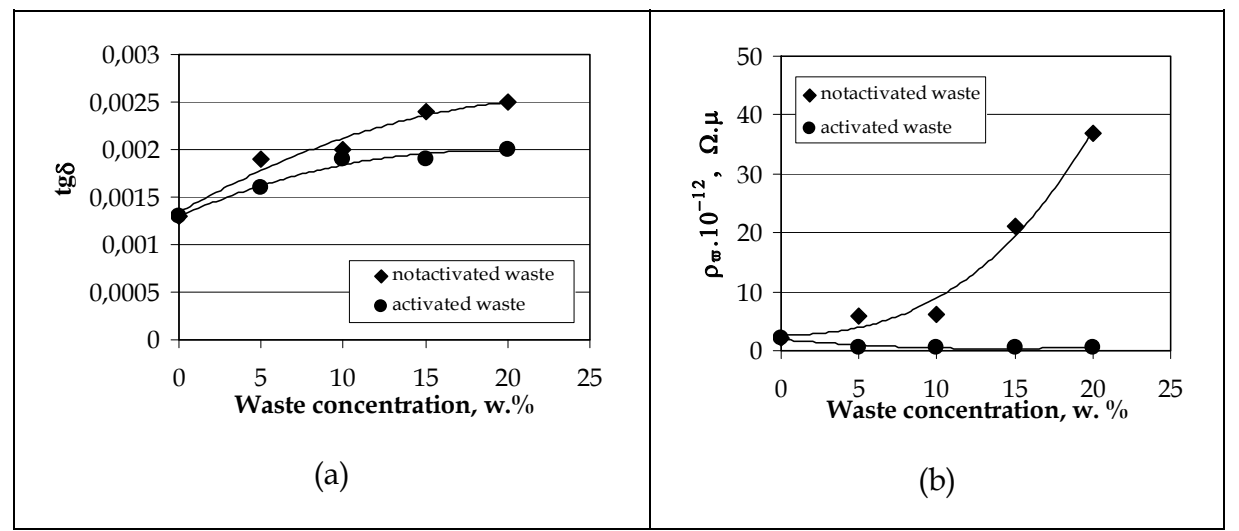

Fig. 17. Dependence of tg $\delta$ at frequency $8 \mathrm{MHz}$ (a) and specific volume resistance values (b) on activated waste amount

In order to improve mainly the composite impact strength modification of UP with polymer additive was experimented. Based on previous studies (Koleva et al., 2005) high impact polystyrene (HIPS, Neftohim, Bulgaria) as a $40 \mathrm{w}$. \% solution in styrene was used as modifier. From these investigations the optimal HIPS concentration was determined as 10 w. \% from UP weight.

Positive effect of HIPS on composite strength properties was clearly expressed not only with regard to the composite's impact strength (Fig. 18a), but bending and compressive strength as well even though their values decrease with the increase in waste amount (Fig. 19b). 
Lower strength characteristics at higher waste amounts probably result from some processes of filler sedimentation observed at concentrations of more than $10 \mathrm{w} \%$ that causes some anisotropy of strength properties (Koleva et al., 2008d).

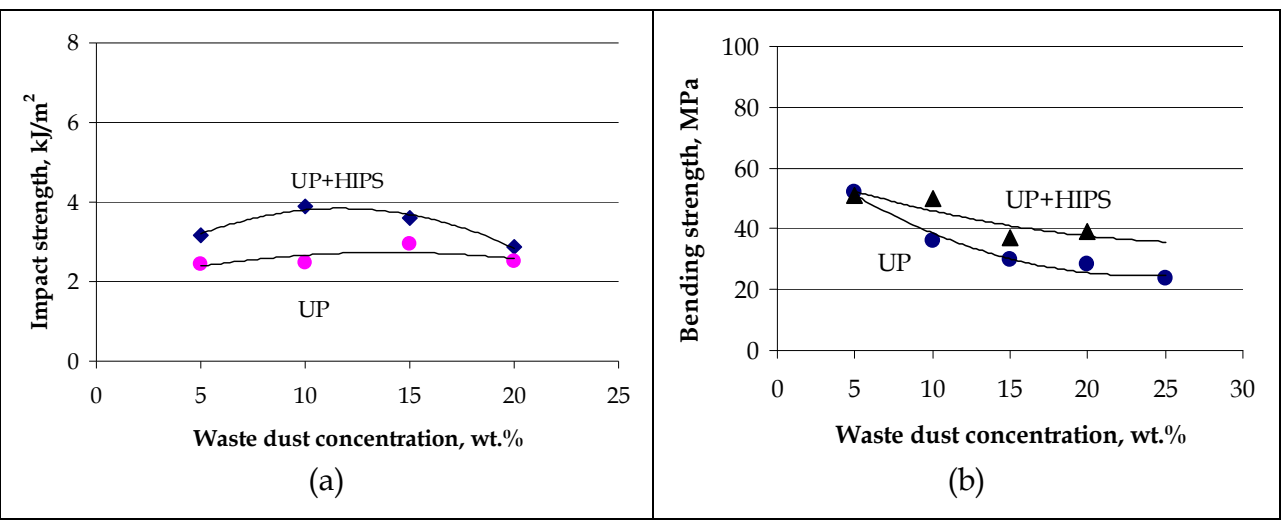

Fig. 18. Strength characteristics of composition based on UP/HIPS: impact strength (a) and bending strength (b) as function of waste amount

The presence of HIPS influences composite electric properties also - for example electric strength becomes slightly lower compared to the composite based on UP (Fig. 19a) - an effect caused by the structural nonhomogeny of the multiphase polymer system UP/HIPS (Koleva et al., 2008) but increases with the increase of waste amount in the composition.

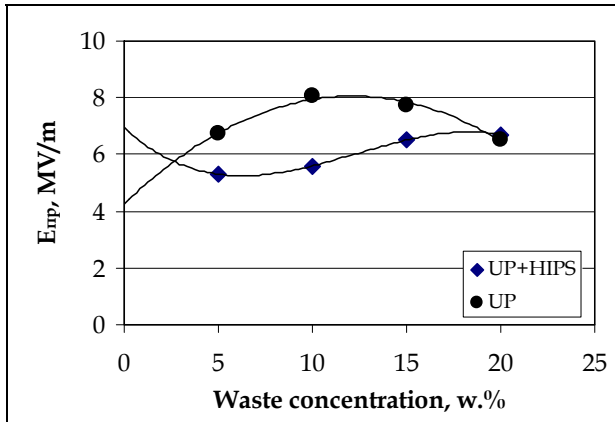

(a)

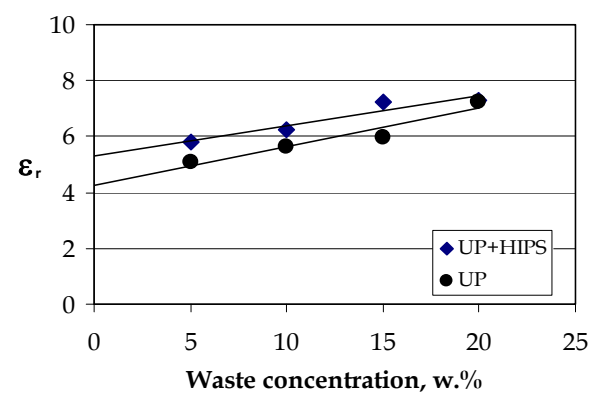

(b)

Fig. 19. Changing of electric strength $\mathrm{E}$ (a) and relative dielectric permeability $\varepsilon_{\mathrm{r}}$ (frequency $1 \mathrm{kHz}$ ) (b) values vs. the waste concentration for composites based on UP and UP/HIPS polymer system

The relative dielectric permeability increases also, because polarizations caused by HIPS superimpose on these ones generated by the polyester (Fig. 19b). Relative dielectric permeability values increase (especially at higher frequency) because of additional polarizations generated by the HIPS.

Values of $\operatorname{tg} \delta$ and specific volume resistance $\rho_{\mathrm{v}}$ are higher for composites based on UP/HIPS, especially at lower frequency (Fig. 20a) because of dropping out of the slow 
polarizations. At the same time the values of conductivity for these composites decrease, that means the losses caused by conductivity decrease also.

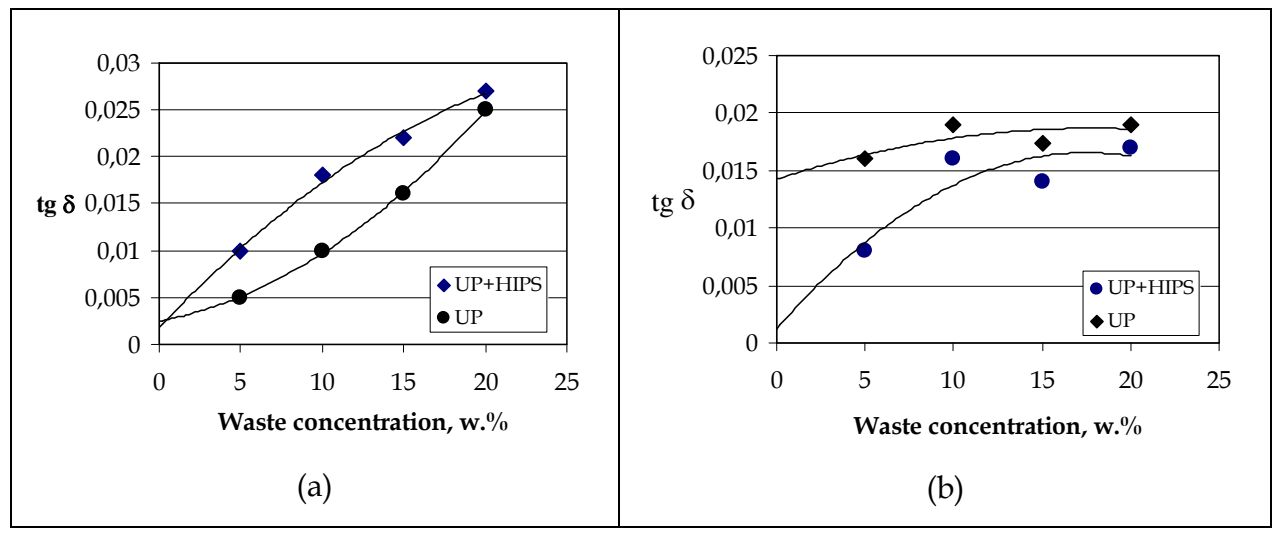

Fig. 21. Dependencies of $\operatorname{tg} \delta$ on the waste content for composites based on UP and UP/HIPS at frequencies $1 \mathrm{kHz}(\mathrm{a})$ and $8 \mathrm{MHz}(\mathrm{b})$

Dielectric losses become greater at higher waste concentration both at low and high frequency because of the part of them due to the waste increases - that is very well expressed at low frequency (Fig. 20b) (Koleva, 2008e).

\section{Conclusions}

A large number of waste materials have been studied as possible component of inorganic and organic polymer composites with specific characteristics and application. The tests carried out and the analysis of the results obtained considering the composite properties allow us to draw the following conclusions:

1. The waste ferronickel slag generated from the "refining" and "melting" processes, and waste glass from windows, containers and TV-monitors are suitable for wide application: direct - as filters with various application, glazes, etc., and indirect - as raw material for production of new materials useful for other productions (aerators, diffusers, ceramic filters, catalyst carriers, compact and porous glass-ceramics, etc.). The industrial waste slag and glass allow the production of composites with preassigned properties by the classical techniques of the ceramic technology. By using fractions of slag and glass with different ratio and grain size, as well as by addition of pore-creator, the production of composites with controlled microstructure and porosity (unilayer and multilayer (gradient)) is possible.

2. The composite materials developed on the basis of unsaturated polyester resins and gypsum-fiber filler show relatively good strength characteristics and can find application in the machine-building industry for the production of housings and other parts, replacing other materials with similar parameters, but of higher cost. The materials based on epoxy resins are better electro insulators and could be successfully used for electrical insulation compounds with application in electrical constructions, radio-electronics circuitry and other types of electrical equipment and appliances. 
3. Grinded rubber waste could be used as filler in polymer composite materials based on unsaturated polyester resins. Filler's content should not exceed $12 \mathrm{w}$. \% - otherwise the engineering properties of the resin deteriorate. The composition with $7 \mathrm{w}$. \% shows optimal thermal characteristics and could be applied for thermal insulation materials. Although the values of some electric characteristics fall down, the compositions obtained keep their electric strength and specific volume resistance enough high, and the values of the relative dielectric permeability and the tangent of the dielectric losses angle low, which makes their use possible in electric insulating materials. The acceptable values of the absorption coefficient offer a good possibility for application of the composites containing rubber waste materials for noise isolation products (walls, plates, cylinders etc.).

4. The presence of waste dust from power production influences the strength and electric characteristics of the polymer compositions based on UP. This influence depends on the amount of the waste in the composition. The waste improves the electric strength, but lowers the relative dielectric permeability. Although this effect the composite possess enough good electric characteristics and could be used for electric insulation materials.

\section{Acknowledgments}

The authors extend their grateful acknowledgement to prof. Milosav Milosevski for his support in the synthesis and characterization of the inorganic composites.

\section{Reference}

Asdrubali, F. (2006). Survey on the acoustical properties of new sustainable materials for noise control, Euronoise 2006, Tampere - Finland, June 2006, pp 1-10.

Aules, W. A. (2011). Utilization of Crumb Rubber as Partial Replacement in Sand for Cement Mortar. European Journal of Scientific Research, Vol.51, No.2, pp.203-210.

Covas, J. A. et al. (1995). Rheological Fundamentals of Polymer Processing, Kluwer Academic Publishers, Niederland.

Ding, Z. et al.(2010). Research on Comprehensive Utilization of Waste Rubber and Aged Asphalt. Applied Mechanics and Materials, Vol. 34-35, pp.1526

Electric Power Industry: Largest US Toxic Polluter (n. d.) In source: http://www.mindfully.org/Energy/Power-Industry-Polluter.htm

Fidancevska, E.; Vassilev, V.; Milosevski, M.; Parvanov, S.; Milosevski, D. \& Aljihmani, L. (2006). Composites on the base of industrial wastes. I. Physicochemical properties of Fe-Ni slag, Journal of the University of Chemical Technology and Metallurgy, Vol.41, No.4, pp. 431-438, ISSN 1311-7629.

Fidancevska, E.; Vassilev, V.; Milosevski, M.; Parvanov, S.; Milosevski, D. \& Aljihmani, L. (2007). Composites based on industrial wastes III. production of composites of Fe$\mathrm{Ni}$ slag and waste glass, Journal of the University of Chemical Technology and Metallurgy, Vol.42, No.3, pp. 285-290, ISSN 1311-7629

Fidancevska, E.; Vassilev, V.; Hristova-Vasileva, T. \& Milosevski, M. (2009). On a possibility for application of industrial wastes of metallurgical slag and TV-glass, Journal of the University of Chemical Technology and Metallurgy, Vol. 44, No.2, pp. 189-196, ISSN 1311-7629.

Heckl, M. \& Mueller, H.A.(1995). Taschenbuch der Technischen Akustik. Springler-Verlag, Berlin. 
Khalid, H. A.; Artamendi, I. (2004). Mechanical Properties of Used - Tyre Rubber. Engineering Sustainability, 157, pp. $37-43$.

Koleva, M., Betchev, Ch. \& Zheglova, A. (2003). Rubber Waste / Polyesters Compositions for Insulation Materials. Proceedings of 10 th International Conference on Mechanics and Technology of composite Materials, Sofia, September, 2003.

Koleva, M., \& Boyadjiiski, G. (2005). Influence of the mixing conditions on the physicomechanical properties of the polymer system NPES/UPS, J. Techn. Univ. Gaborovo. Vol. 32, pp. 9-13, ISSN 1310-6686

Koleva, M. (2005). Rubber waste/UP polymer systems for insulation materials. Proceedings of 6th International Scientific Conference "Advances in plastics technology" APT'05, pp. 2005, ISBN 83-917693-4-8, Katowice, Poland, November 2005.

Koleva, M., Zheglova, A., Vassilev, V., Fidancevska, E., Milosevski, M., Vassilev, G. (2007). Strength characteristics of polymer composites with waste dust from power production. Proceedings of International Scientific Conference UNITEH'07, ISSN 1313230X, Gabrovo, Bulgaria, November 2007.

Koleva, M., Vassilev, V., Vasilev, G.(2008). Polymer composites containing waste dust from power production. I. Influence of particles' mechanical activation on composition's strength characteristics. Macedonian Journal of Chemistry and Chemical Engineering, Vol.27, N 1, pp 41-46, ISSN 1857 - 5552.

Koleva, M., Vassilev, V., Vasilev, G.(2008). Polymer composites containing waste dust from power production. II. Strength characteristics of composites based on UP/HIPS polymer system. Macedonian Journal of Chemistry and Chemical Engineering, Vol.27, N 1, pp 47-52, ISSN $1857-5552$

Koleva, M., Zheglova, A. \& Vassilev, V.(2008). Polymer composites containing waste dust from power production. I. Impact of waste mechanical activation on electric properties of the polymer composite. Journal of the Technical University of Gabrovo, Vol. 36, pp. 64-69.

Koleva, M., Zheglova, A. \& Vassilev, V.(2008). Polymer composites containing waste dust from power production. II. Electrical properties of polymer composites based on UP/HIPS polymer system. Journal of the Technical University of Gabrovo, Vol. 36, pp. 70-74.

Koleva, M., Zheglova, A. \& Vassilev, V. (2008). Strength characteristics of polymer composites with mechanically activated waste dust from power production. Proceedings of International Scientific Conference UNITECH'08, Vol.2, Gabrovo, Bulgaria, November, 2008.

Lipatov, Y.S. (Ed.). (1986). Physical chemistry of multicomponent polymer systems. Naukova dumka, Kiev, Ukraine.

Pasinkov V.V.\& Sorokin V.S. (1986).Electronics Materials, Vishaia shkola, Moskow, 1986.

Pemikis R. \& Apsite B., (1998). Cellulose ether ionotropic gelsq their properties and applications.Chemistry and Technology, Vol.32, No 5-6, pp. 397-403.

Petkov, S., Koleva, M \& V. Lazarova. (1999). Mechanical characteristics of rubber filled polyester. Proceedings of International Conference TECHNOMER '99, ISBN 3-000012510-8, Chemnitz, Germany, November 1999.

Petkov, S., Koleva, M. \& V. Lazarova. (2001). Sound Dumping and Thermal Isulation properties of Plyester- Rubber aste Compositions. Proceedings of International 
Conference TECHNOMER '2001, ISBN 3-00-008212-3, Chemnitz, Germany, September, 2001.

Rodriguez, E. L. (1988). The effect of cryogenically ground rubber on some mechanical properties of an unsaturated polyester resin. Polym. Eng. Sci., Vol. 28 N 22, pp. 1455-1461.

Sathiyamoorthy, M.; Thanappan, S.\& Senthilkumar M. (2011). Utilization of waste rubber tires as an additional ingredient of concrete mixtures. International J. of Engg. Research E Indu. Appls. Vol.4, No. I (February 2011), pp. 335-350.

Siddique R. \& Naik, T. R.. (2004). Properties of concrete containing scrap-tire rubber - an overview. Waste Management, Vol 24, N 6, pp. 563-569.

Soontaranum, W., Higgins, J. S. \& Papathanasiou, T. D. (1996). Rheology and thermodynamics in partially miscible polymer blends. J. Non-newtonian Fluid Mech., vol. 67, N 1-3, pp. 191-212.

Stelmachowski, M. \& Słowiński K. (2009). Conversion of waste rubber as an alternative rout to renewable fuel production. In: Energy and Sustainability II, Edited By: Mammoli, A.A.; Brebbia, C.A. \& Popov, V., pp 489 - 499, WIT Press, London, UK.

Stelmachowski, M. \& Słowiński, K. (2010). Feedstock recycling of plastic wastes and scrap rubber via thermal cracking. In: Environmental Engineering III. Edited by Pawłowski, A., Taylor \& Francis Group, London, pp. 317-324.

Trofimov N.N.\& Konovich M.Z. (1999). Principles of the Creation of Polimer Compositions, Nauka, Moscow, Russia.

Tunsan, M. (2003). The Use of Waste Materials in Asphalt Concrete Mixtures. Waste Management and Research, Vol. 21, № 2, pp. 83 - 92.

Vassilev, V.; Fidancevska, E.; Milosevski, M.; Parvanov, S.; Milosevski, D. \& T. HristovaVasileva. (2007). Composites based on industrial wastes. IV. Production of porous composites from Fe-Ni slag and waste glass, Journal of the University of Chemical Technology and Metallurgy, Vol.42, No.4, pp. 369-376, ISSN 1311-7629.

Vassilev, V.; Fidancevska, E.; Milosevski, M.; Parvanov, S.; Milosevski, D. \& T. HristovaVasileva. (2007). Composites on the base of industrial wastes. II. Physicochemical properties of waste glass, Journal of the University of Chemical Technology and Metallurgy, Vol.42, No.2, pp. 175-180, ISSN 1311-7629

Yesilata, B., Isıker, Y., Turgut, P. (2009). Thermal insulation enhancement in concretes by adding waste PET and rubber pieces. Construction and Building Materials, Vol. 23, pp. $1878-1882$

Zheglova, A. \& Rashev, G. (2001). Properties of Composite Materials from Unsaturated Polyester Resin, Zbornik radova proceedings, p. 141 - 146, 2001.

Zheglova A.\& Rashev G.(2002). Properties of Composite Materials from Unsaturated Polyester Resins, $5^{\text {th }}$ International Conference on Accomplishments of Electrical and Mechanical Industries, Banja Luka, Republic of Srpska, 2002.

Zheglova A.; G. Rashev. (2003). Mechanical and Electrical Properties of Composite Materials based on Polyester Resins and Gypsymfiber. Proceedings of International Conference TECHNOMER'2003, (ISBN 3-00-008212-3) Chemnitz, Germany, November 2003,

Zheglova, A., Koleva, M., Vassilev, G., Boycheva, S. \& Parvanov, S. (2007). Electrical characteristics of polymer composites containing waste dust from power production. Proceedings of International Scientific Conference UNITECH'07, vol.2, Gabrovo, November, 2007, ISSN 1313-230X 


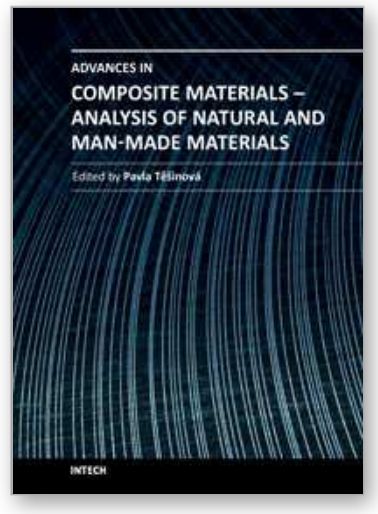

\author{
Advances in Composite Materials - Analysis of Natural and Man- \\ Made Materials \\ Edited by Dr. Pavla Tesinova
}

ISBN 978-953-307-449-8

Hard cover, 572 pages

Publisher InTech

Published online 09, September, 2011

Published in print edition September, 2011

Composites are made up of constituent materials with high engineering potential. This potential is wide as wide is the variation of materials and structure constructions when new updates are invented every day.

Technological advances in composite field are included in the equipment surrounding us daily; our lives are becoming safer, hand in hand with economical and ecological advantages. This book collects original studies concerning composite materials, their properties and testing from various points of view. Chapters are divided into groups according to their main aim. Material properties are described in innovative way either for standard components as glass, epoxy, carbon, etc. or biomaterials and natural sources materials as ramie, bone, wood, etc. Manufacturing processes are represented by moulding methods; lamination process includes monitoring during process. Innovative testing procedures are described in electrochemistry, pulse velocity, fracture toughness in macro-micro mechanical behaviour and more.

\title{
How to reference
}

In order to correctly reference this scholarly work, feel free to copy and paste the following:

Milena Koleva, Anka Zheglova, Venceslav Vassilev and Emilija Fidancevska (2011). Composites Containing Waste Materials, Advances in Composite Materials - Analysis of Natural and Man-Made Materials, Dr. Pavla Tesinova (Ed.), ISBN: 978-953-307-449-8, InTech, Available from:

http://www.intechopen.com/books/advances-in-composite-materials-analysis-of-natural-and-man-madematerials/composites-containing-waste-materials

\section{INTECH}

open science | open minds

\section{InTech Europe}

University Campus STeP Ri

Slavka Krautzeka 83/A

51000 Rijeka, Croatia

Phone: +385 (51) 770447

Fax: +385 (51) 686166

www.intechopen.com

\section{InTech China}

Unit 405, Office Block, Hotel Equatorial Shanghai

No.65, Yan An Road (West), Shanghai, 200040, China

中国上海市延安西路65号上海国际贵都大饭店办公楼 405 单元

Phone: +86-21-62489820

Fax: $+86-21-62489821$ 
(C) 2011 The Author(s). Licensee IntechOpen. This chapter is distributed under the terms of the Creative Commons Attribution-NonCommercialShareAlike-3.0 License, which permits use, distribution and reproduction for non-commercial purposes, provided the original is properly cited and derivative works building on this content are distributed under the same license. 